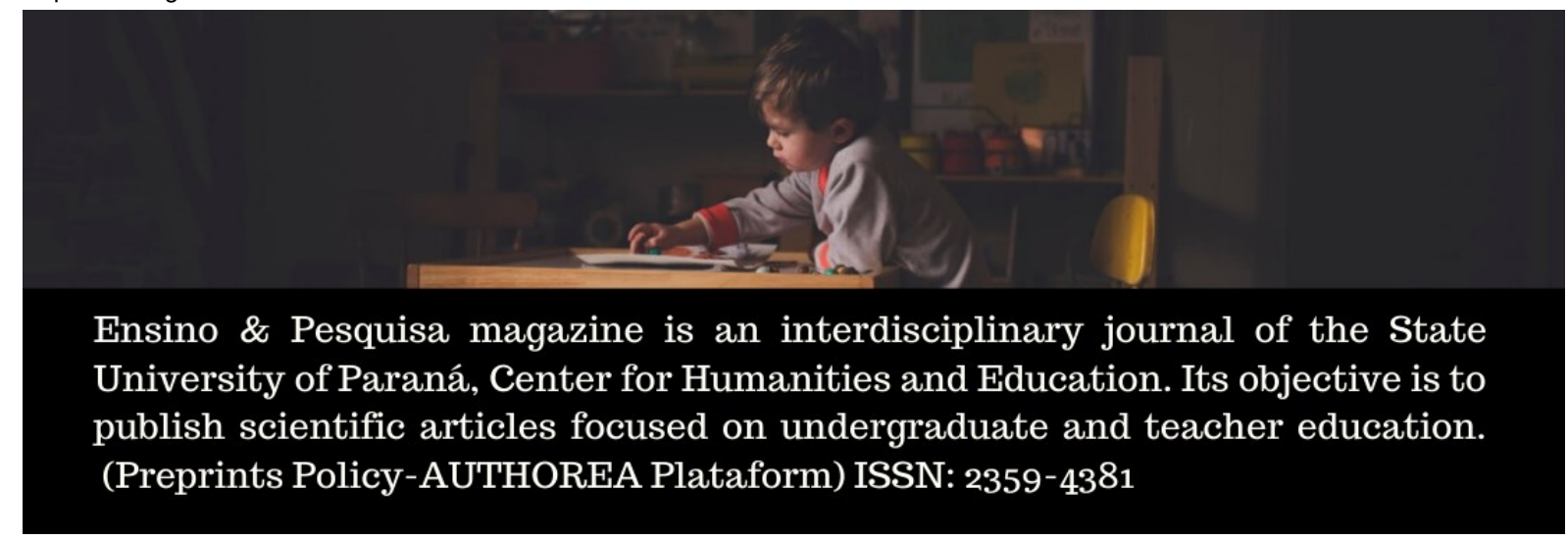

\title{
Panorama dos artigos sobre Atividades Experimentais publicados na Revista Brasileira de Ensino de Física no período compreendido entre 2002 e 2017
}

Sheila Magali Holz, Doutoranda pelo Programa de Pós-Graduação em Educação em Ciências e Química da Vida e Saúde da Universidade Federal de Santa Maria (PPGECQVS/UFSM), Mestre em Física Teórica pelo Instituto de Física Teórica da Universidade Estadual Paulista Júlio Mesquita (IFT/UNESP), professora de Física do Colégio Militar de Santa Maria (CMSM/RS), holz_sheila@yahoo.com.br

Orildo Luis Battistel, Pós-Doutorando pelo Programa de Pós-Graduação em Educação em Ciências e Química da Vida e Saúde da Universidade Federal de Santa Maria (PPGECQVS/UFSM), Doutor em Física Teórica pela Universidade de São Paulo (USP), mestre em Física Teórica pela Universidade de São Paulo (USP), professor de Física do Colégio Militar de Santa Maria (CMSM/RS), orildobat@yahoo.com.br

Inés Prieto Schmidt Sauerwein, doutorada em Educação Científica e Tecnológica pela Universidade Federal de Santa Catarina (UFSC), mestre em Ensino de Ciências (Modalidade Física e Química) pela Universidade de São Paulo (USP), professora adjunta da Universidade Federal de Santa Maria (UFSM/RS), ines.ufsm@gmail.com

Resumo: Objetivando conhecer como as atividades experimentais estão sendo abordadas na literatura especializada, realizamos uma revisão bibliográfica que abarcou todos os artigos publicados na Revista Brasileira de Ensino de Física no período compreendido entre os anos de 2002 e 2017. Os 138 artigos encontrados versando sobre essa temática foram classificados em relação ao nível de ensino a que foram destinados e quanto aos seus aspectos metodológicos em: i) Função Didática: Atividades de Demonstração, Verificação e Investigação; ii) Promoção de Conteúdos Procedimentais; iii) Processo de Construção do Aparato Experimental: Ênfase no uso de tecnologia, de material de baixo custo e na montagem de equipamentos. No estudo realizado, verificamos que a maioria das publicações se refere ao processo de construção e aperfeiçoamento de atividades experimentais e são destinadas ao ensino superior.

Palavras-chave: Atividades Experimentais. Ensino de Física. Função Didática.

Overview of the articles on Experimental Activities published in the Brazilian Journal of Physics Education from 2002 to 2017

Abstract: Aiming to know how experimental activities are being addressed in the specialized literature, we carried out a bibliographic review that covered all articles published in the Revista Brasileira de Ensino de Física in the period between the years 2002 and 2017. The 138 articles found dealing with this theme were classified in relation to the level of education to which they were assigned and as to their methodological aspects in: i) Didactic Function: Demonstration, Verification and Investigation Activities; ii) Promotion of Procedural Content; iii) Experimental Apparatus Construction Process: Emphasis on the use of technology, 
low-cost material and equipment assembly. In the study, we found that most publications refer to the process of building and improving experimental activities and are aimed at higher education.

Palavras-chave: Atividades Experimentais. Ensino de Física. Função Didática.

Submissão: 2019-11-07. Aprovação: 2020-04-17. Publicação: 2020-04-17

\section{INTRODUÇÃO}

https://doi.org/10.33871/23594381.2020.18.1.136-166

A preocupação com o ensino de Física não é recente e muito menos uma exclusividade brasileira. Em 1955, iniciou-se nos Estados Unidos um movimento de renovação do ensino de ciências, que até então era realizada por meio de manuais, dando destaque a atividades experimentais. No Instituto de Tecnologia de Massachusetts (MIT), em 1956, foi criado o Physical Science Study Committee (PSSC), apresentando como proposta abordar os conteúdos físicos de uma maneira menos abstrata que os livros da época, dando ênfase na conceitualização em detrimento a matematização, buscando dar suporte ao professor na parte teórica e experimental (ALVES FILHO, 2000). Em meio à guerra fria, os Estados Unidos da América, viram-se ultrapassados tecnologicamente pela União Soviética, o que se evidenciou após o lançamento do satélite "Sputnik I". Tentando modificar esse cenário, investiu-se maciçamente em educação e tecnologia, surgindo assim o PSSC buscando despertar o interesse dos jovens para área da Física, através de um ensino mais experimental. Em 1962 o PSSC chegou ao Brasil por meio do IBECC (Instituto Brasileiro de Educação, Ciência e Cultura) em parceria com a UNESCO (Organização das Nações Unidas para Educação, Ciência e Cultura). Alguns anos mais tarde (1962), em Harvard, inicia-se outro projeto o Project Physics Coursen Committee e seu sucessor o Project Physics Course, (HOLTON, 2003), que foi estruturado e reelaborado entre os anos de 1962 a 1972. Apresentando uma ampla gama de recursos de aprendizagem e um sistema multimídia integrado, incluindo textos, filmes, experimentos com aparelhos de laboratório especialmente coordenados, folhetos de instruções programados, transparências, manual do aluno e livro de recursos do professor. No âmbito nacional, o Projeto de Ensino de Física (PEF) (IFUSP, 1980), elaborado no Departamento de Física Experimental do Instituto de Física da Universidade de São Paulo, publicado em 1980, foi criado com o objetivo de facilitar o aprendizado de física no segundo grau. A coleção era composta de 4 fascículos e três conjuntos experimentais. Antes da edição ela foi utilizada em 20 escolas públicas de São Paulo por cerca de 3000 estudantes, durante os anos de 1971 e 1972. O Guia abordava Mecânica, Eletricidade e Eletromagnetismo, e entre seus objetivos constava: "levar o aluno a conhecer alguns fenômenos e conceitos de Física, de modo que possa operar com esses conceitos, resolver problemas e realizar experiências simples".

Nesses e em muitos outros movimentos de reforma curricular foi dado destaque ao ensino no laboratório. A prática experimental tinha sua inserção, à medida que fazia a inter-relação com a teoria no desenvolvimento da Física, pois, a abordagem tradicional, com sua ênfase na instrução formal, colocando o estudante como um recebedor passivo de conhecimento acumulado, deveria ser abandonada (HODSON, 1998).

Shulman \& Tamir (p. 1119, 1964) salientam que "novos currículos que enfatizam os processos da ciência e o desenvolvimento de habilidades cognitivas superiores, dão ao laboratório um papel central, não apenas como um local para demonstração e confirmação, mas como o núcleo do processo de aprendizado da ciência". Sobre o uso do laboratório

Ensino \& Pesquisa, União da Vitória, v. 18, n 1, p. 136-166, jan./abr., 2020. 
Ausubel (1968) afirma que ele proporciona aos estudantes a possibilidade da resolução de problemas, a capacidade analítica e de generalização, além de fornecer uma certa compreensão da natureza da ciência. A atividade experimental é considerada um recurso didático importante, onde o aluno é visto como protagonista do ensino, porém, para que isso ocorra, as atividades devem ser desenvolvidas para esse fim tirando o estudante da passividade e colocando-o como sujeito ativo, que elabora hipóteses e estratégias, desenvolve argumentos e trabalha coletivamente.

As atividades experimentais podem ter diferentes objetivos, finalidades e metodologia. Moreira e Levandowisk (1983) apresentam três objetivos: a aprendizagem de habilidades, técnicas e manuseio de aparelhos; a aprendizagem da experimentação e a aprendizagem de conceitos, relações, leis e princípios. Trumper (2003) cita como objetivo despertar atitudes como curiosidade, objetividade, precisão e cooperação em equipe. Laburú (2006) apresenta aspectos para que as atividades experimentais tenham função motivacional. Hodson (1998) cita muitos outros objetivos como: desenvolver habilidades básicas de observação, ilustrar um princípio teórico, coletar dados, testar uma hipótese, demonstrar um fenômeno, desenvolver habilidades básicas de medidas, adquirir familiaridade com aparatos, proporcionar um "espetáculo de luzes, estrondos e espumas", estimular a confiança e a autoestima dos alunos, demonstrar o poder de previsão da teoria ainda em desenvolvimento e, como objetivo principal, mostrar que os aprendentes podem investigar e solucionar problemas ou no mínimo tentar. Além disso, pode-se considerar a atividade experimental como um instrumento didático (ALVES FILHO, 2000) que busca modificar a postura do estudante que vai de passivo para ativo.

Por tudo isso, percebemos a riqueza do uso das atividades experimentais no ensino de Física e sentimos a necessidade de analisar a evolução dos artigos publicados sobre esse tema em nosso país nos últimos anos. Para isso, analisamos por um período de 16 anos as publicações referentes às atividades experimentais, em uma revista de ampla abrangência e que tem como público pesquisadores, estudantes de pós-graduação e graduação, professores de Física em todos os níveis e a comunidade envolvida na pesquisa e desenvolvimento de métodos e materiais para o ensino desta disciplina. Abib e Araújo (2003) realizaram uma revisão bibliográfica sobre atividades experimentes no período de 1992 à 2001, de forma complementar, nosso período analisado corresponde aos anos de 2002 à 2017.

\section{Materiais e métodos}

Para a análise realizada o periódico escolhido foi a Revista Brasileira de Ensino de Física (RBEF), da Sociedade Brasileira de Física, abarcando todos os volumes publicados trimestralmente pela revista, no período de dezesseis anos, ao qual nos detivemos. A escolha desse periódico refere-se ao fato da revista ser exclusiva ao Ensino de Física e possibilitar livre acesso a estudantes, professores e pesquisadores. Para executarmos a pesquisa bibliográfica seguimos as etapas preconizadas por Gil (2017). Inicialmente, realizamos uma busca manual identificando os artigos publicados entre os números 24 e 39 (cada número com 4 volumes. Encontramos 138 artigos relativos à atividades experimentais, por considerar esse número bastante expressivo e para viabilizar a descrição desses, optou-se por analisar somente um periódico. 


\section{Panorama geral das publicações}

Após uma leitura explanatória dos 1273 artigos publicados, a partir de seu título e resumo, verificamos que 138 artigos, aproximadamente $10,8 \%$ do total, estavam relacionados com atividades experimentais.

No Gráfico 1, apresentamos os totais de artigos publicados em cada ano, sobre o tema em estudo. Percebe-se, a partir de 2007, um acréscimo considerável no número de publicações relacionadas com atividades experimentais, demonstrando um maior interesse no assunto. Uma das possíveis causas desse aumento expressivo é a preocupação crescente dos professores em variar os recursos didáticos para motivar os alunos ao ensino de Física, por meio da adoção de estratégias construtivistas. Isso confirma o que afirmam Shulman e Tamir (1988) que ao justificarem a importância do uso do laboratório no ensino de ciências enumeram alguns benefícios, entre eles o de despertar e manter interesse, atitude, satisfação, mente aberta e curiosidade na ciência. Segundo (BORGES, 2002), o ensino prático tem ganhado importância e prestígio devido a popularização das ideias progressistas ou desenvolvimentistas no pensamento educacional. Além disso, mudanças em políticas públicas com a finalidade de fomentar e ampliar a pós-graduação no país (BRASIL, 2005) foram exitosas como pode ser visualizado em números: "Se, em maio de 2004, havia 2.993 cursos de mestrado e doutorado, em 2014 este número saltou para 5.670" (OLIVEIRA, 1968). Vosgerau e Romanowski (VOSEGERAU; ROMANOWSKI, 2014) enfatizam que a contínua expansão dos programas de pós-graduação, acarretou em um aumento significativo no número de publicações das pesquisas realizadas.

Gráfico 1 - Número de artigos sobre atividades experimentais publicados na RBEF entre 2002 e 2017.

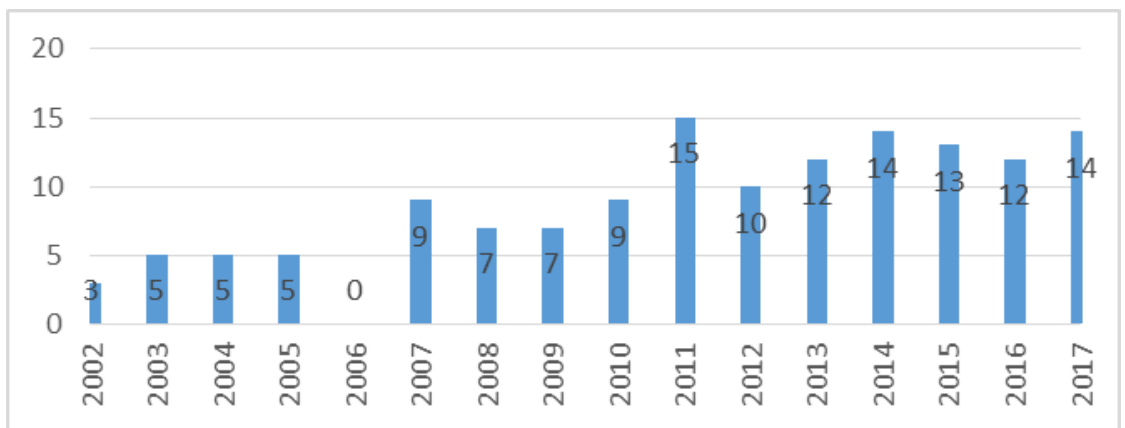

Fonte: Elaborado pelos autores

Com base em uma primeira leitura explanatória dessas obras (GIL, 2017) as mesmas foram classificadas quanto à sua temática e nível escolar ao qual se destinam. $\mathrm{O}$ Quadro 1 apresenta a distribuição geral dos artigos selecionados em relação a esses quesitos. Chama-nos atenção a grande disparidade quanto ao nível de ensino, com evidente concentração no ensino superior. 
Quadro 1 - Classificação dos artigos sobre atividades experimentais, por nível de escolaridade e temática, publicados na RBEF entre 2002 e 2017.

\begin{tabular}{|c|c|c|c|c|c|}
\hline & $\begin{array}{c}\text { Ensino } \\
\text { Fundamental }\end{array}$ & $\begin{array}{c}\text { Ensino } \\
\text { Médio }\end{array}$ & $\begin{array}{c}\text { Ensino } \\
\text { Superior }\end{array}$ & $\begin{array}{c}\text { Formação de } \\
\text { Professores }\end{array}$ & Total \\
\hline Mecânica & - & 6 & 22 & - & 28 \\
\hline Óptica & - & 7 & 15 & - & 23 \\
\hline Acústica & - & 1 & 3 & - & 4 \\
\hline Eletromagnetismo & - & 1 & 25 & - & 26 \\
\hline Física Moderna & - & - & 11 & - & 11 \\
\hline Calorimetria & - & - & 9 & - & 9 \\
\hline Hidrodinâmica & 1 & - & 6 & - & 7 \\
\hline Gases & - & - & 2 & - & 2 \\
\hline Astronomia & - & - & - & 1 & 1 \\
\hline Ondulatória & - & - & 11 & - & 11 \\
\hline Multitemático & - & 2 & 7 & & 9 \\
\hline $\begin{array}{c}\text { Revisão ou } \\
\text { Fundamentação } \\
\text { Teórica }\end{array}$ & \multicolumn{7}{|l|}{7} & 112 & 1 & 7 \\
\hline Total por nível & 1 & 17 & & \\
\hline
\end{tabular}

Fonte: Elaborado pelos autores

Apesar de encontrarmos artigos em todas as áreas da Física, verifica-se uma grande incidência em algumas áreas de estudo. As áreas do conhecimento com maior número de publicações são: Mecânica, Eletromagnetismo e Óptica. Essas três áreas juntas correspondem a 53,6\% de todas as publicações do período analisado.

Outro resultado bastante evidente é que a ampla maioria dos artigos publicados, $81,2 \%$, são destinados ao Ensino Superior, enquanto apenas 12,3\% são destinados ao Ensino Médio. Quando observamos o número de publicações direcionadas ao Ensino Fundamental, vemos que esse número cai ainda mais, identificando-se apenas uma publicação, o que corresponde a $0,7 \%$ das publicações.

Cabe ressaltar que dois artigos publicados nesse período não são passíveis de serem classificados de acordo com os critérios que adotaremos para os demais, por este motivo estes serão analisados separadamente. Eles são artigos de revisão, semelhantes ao que realizamos, apresentam estudos sobre publicações realizadas com respeito às atividades experimentais. Por este motivo nós os consideramos como bastante relevantes para o nosso trabalho já que ajudam a elucidar o panorama sobre as publicações, além do que, por ocorrerem em períodos diferentes, fornecem excelentes parâmetros de comparação. Vamos discorrer brevemente sobre eles.

Em um trabalho de revisão Abib e Araújo (2003) publicaram os resultados de um estudo realizado com 106 artigos referentes a publicações sobre a utilização da experimentação como estratégia de ensino, analisando os trabalhos publicados entre $1992 \mathrm{e}$ 2001 na Revista Brasileira de Ensino de Física e também no Caderno Catarinense de Ensino de Física. No referido trabalho os artigos foram classificados em relação às áreas temáticas, revelando que as áreas mais privilegiadas foram as de Mecânica, 
Eletromagnetismo e Óptica e as menos abordadas foram as de Calorimetria, Gases, Ondulatória, Hidrodinâmica e Astronomia. O grau de concentração das atividades experimentais nas áreas do conhecimento também foi verificado, de modo que as três primeiras somavam juntas $74,0 \%$ do total de artigos. $O$ trabalho mostrou que sobre a temática Acústica, no período compreendido entre 1992 e 2001, não foi abordado em nenhum artigo. Os autores também realizaram uma análise dos artigos classificando-os quanto aos diferentes aspectos metodológicos relacionados às atividades experimentais, nas seguintes classes: a) Ênfase matemática, diferenciando-os em qualitativo e quantitativo; b) Grau de direcionamento, em que foram relacionados como de demonstração, de verificação ou de investigação, os que propõem atividades com maior afinidade com o ensino tradicional ou com um método investigativo de abordagem construtivista; c) Uso de novas tecnologias; d) Cotidiano; e) Montagem de equipamentos.

Para facilitar a comparação entre as duas pesquisas, analisamos o artigo de Araújo e Abib (2003) com um filtro e nos concentramos apenas nos artigos referentes à Revista Brasileira de Ensino de Física, que são 36 do total de 106 artigos analisados. O Gráfico 2 apresenta o número de artigos publicados em cada ano, segundo o trabalho intitulado Atividades Experimentais no Ensino de Física: Diferentes Enfoque, Diferentes Finalidades. Podemos verificar que a média de trabalhos publicados nesse período foi de apenas 3,6 por ano, enquanto que no período que analisamos (2002 a 2017) temos uma média de 8,63 artigos por ano, demonstrando uma substancial elevação neste número.

Gráfico 2 - Número de artigos sobre atividades experimentais publicados na RBEF entre 1992 e 2001.

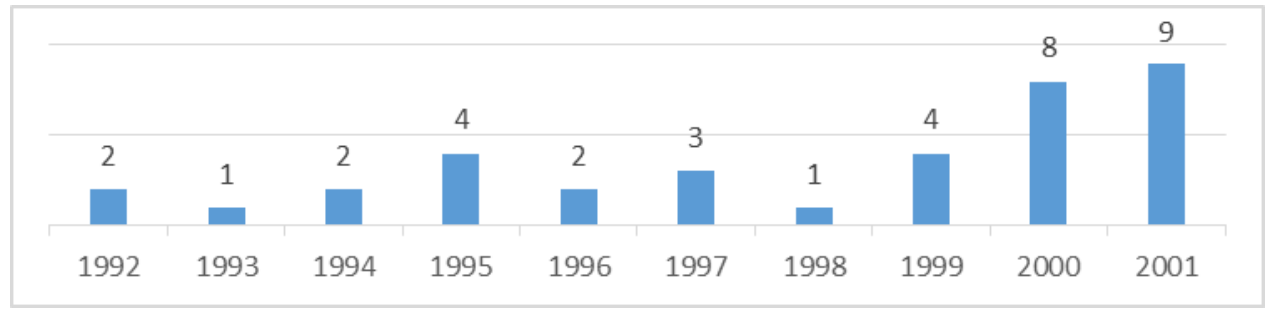

Fonte: Elaborado pelos autores

O Quadro 2 apresenta a temática da atividade experimental abordada no trabalho e o nível escolar ao qual o mesmo se destina. Aqueles que não foram possíveis enquadrar de acordo com o nível de ensino eram os que possuíam apenas proposta de construção do aparato experimental.

Quadro 2 - Classificação dos artigos sobre atividades experimentais, por nível de escolaridade e temática, publicados na RBEF entre 1992 e 2001.

\begin{tabular}{|c|c|c|c|c|c|c|}
\hline & $\begin{array}{c}\text { Ensino } \\
\text { Fundamental }\end{array}$ & $\begin{array}{c}\text { Ensino } \\
\text { Médio }\end{array}$ & $\begin{array}{c}\text { Ensino } \\
\text { Superior }\end{array}$ & $\begin{array}{c}\text { Formação de } \\
\text { Professores }\end{array}$ & Indefinido & Total \\
\hline Mecânica & - & 3 & 4 & 3 & 1 & 11 \\
\hline Óptica & - & 2 & 1 & - & 4 & 7 \\
\hline Acústica & - & - & - & - & - & - \\
\hline Eletromagnetismo & - & - & 3 & - & 1 & 4 \\
\hline Física Moderna & - & 1 & 2 & - & - & 3 \\
\hline Calorimetria & - & - & - & - & 1 & 1 \\
\hline Hidrodinâmica & - & - & - & - & - & - \\
\hline Gases & - & 1 & - & - & - & 1 \\
\hline Astronomia & - & - & 1 & - & - & 1 \\
\hline
\end{tabular}

Ensino \& Pesquisa, União da Vitória, v. 18, nº 1, p. 136-166, jan./abr., 2020. 
Quadro 2 - Classificação dos artigos.....contin.

\begin{tabular}{|c|c|c|c|c|c|c|}
\hline Ondulatória & - & - & 2 & - & - & 2 \\
\hline Multitemático & - & - & & 2 & - & 2 \\
\hline $\begin{array}{l}\text { Revisão ou } \\
\begin{array}{c}\text { Fundamentação } \\
\text { Teórica }\end{array}\end{array}$ & \multicolumn{7}{|c|}{4} & \\
\hline Total por nível & 0 & 7 & 14 & 5 & 6 & 36 \\
\hline
\end{tabular}

Fonte: Elaborado pelos autores

Esses gráficos permitem algumas comparações entre os trabalhos publicados nos dois períodos analisados. No que se refere à temática Formação de Professores, aqueles autores registraram a presença de cinco artigos, correspondendo a 11,1\% dos artigos publicados, enquanto na nossa análise encontramos apenas um artigo sobre o tema, correspondendo a $0,7 \%$ do total. Uma possível explicação para esta discrepância é o fato de que na década de 90, foi divulgada a Declaração Mundial Sobre Educação Para Todos, um plano de ação para satisfazer as necessidades básicas de aprendizagem, elaborada pela UNESCO, além da promulgação da nova Lei de Diretrizes e Bases (9.394/1996), que contribuíram para o surgimento de muitas propostas e cursos de formação de professores e o desenvolvimento de trabalhos de pesquisa sobre o tema.

No trabalho de Abib e Araújo (2003) a distribuição por nível de ensino das atividades experimentais mostra que $19,4 \%$ eram destinadas ao ensino médio e $38,8 \%$ ao ensino superior. Em nossa pesquisa verificamos uma grande disparidade, pois, 81,2 \% eram destinadas ao ensino superior e apenas $12,3 \%$ ao ensino médio. Por outro lado, as temáticas Acústica e Hidrodinâmica não foram contempladas em nenhum artigo no período analisado por aqueles autores, já na pesquisa atual esteve presente em quatro e sete artigos, respectivamente.

Em um trabalho mais específico, Ribeiro e Verdeaux (2012) realizaram uma revisão de artigos sobre experimentação no ensino de Ótica em três periódicos de ampla circulação e disponíveis gratuitamente on-line: Caderno Brasileiro de Ensino de Física, Revista Brasileira de Ensino de Física e Física na Escola durante os anos de 1998 e 2010. Os autores analisaram e classificaram os 64 artigos selecionados por tópicos de estudo, dentro do ensino de Óptica.

\section{Analise dos aspectos metodológicos}

Prosseguindo na análise dos artigos selecionados, por meio de uma releitura mais atenta, minuciosa e detalhista, foi possível conhecê-los melhor e classificá-los a partir de outros critérios que estabelecemos para uma melhor compreensão das publicações encontradas na RBEF no período considerado. Com esse intuito, no que se refere aos seus aspectos metodológicos agrupamos os artigos em três categorias: Função Didática, Promoção de Conteúdos Procedimentais e Processo de Construção do Aparato Experimental.

Visando fornecer uma visão panorâmica dos artigos, elaboramos o Quadro 3 que apresenta as categorias criadas com o número de artigos considerados. 
Quadro 3 - Classificação dos artigos sobre atividades experimentais, publicados na RBEF entre 2002 e 2017 , quanto ao seu aspecto metodológico.

\begin{tabular}{|c|c|c|c|}
\hline \multirow{7}{*}{ Aspectos metodológicos } & \multirow{3}{*}{ Função didática } & Atividades de demonstração & 16 artigos \\
\hline & & $\begin{array}{l}\text { Verificação de modelos } \\
\text { teóricos }\end{array}$ & 11 artigos \\
\hline & & Experimentação investigativa & 15 artigos \\
\hline & $\begin{array}{l}\text { Desenvolvimento de } \\
\text { conteúdos } \\
\text { procedimentais }\end{array}$ & & 24 artigos \\
\hline & \multirow{3}{*}{$\begin{array}{l}\text { Processos de construção } \\
\text { do aparato experimental }\end{array}$} & Ênfase no uso de tecnologias & 16 artigos \\
\hline & & $\begin{array}{l}\text { Ênfase na utilização de } \\
\text { materiais de baixo custo }\end{array}$ & 10 artigos \\
\hline & & $\begin{array}{c}\text { Ênfase na montagem de } \\
\text { equipamentos }\end{array}$ & 40 artigos \\
\hline
\end{tabular}

Fonte: Elaborado pelos autores

Em alguns casos as categorias foram subdivididas visando um estudo mais aprofundado e seletivo. Por possuírem desenvolvimentos mais amplos, determinados artigos se enquadravam, a princípio em mais de uma categoria, por isso estes foram classificados de acordo com a identificação predominante, de modo que todos estão classificados em apenas uma categoria.

\section{a. Função Didática}

$\mathrm{Na}$ categoria função didática agrupamos os artigos que deixavam explícita a sua finalidade. As subcategorias são: Atividades de demonstração, verificação de modelos teóricos e experimentação investigativa.

\section{a.1 Atividade de demonstração}

As atividades de demonstração, apesar de fundamentar-se em conceito científicos, formais e abstratos, têm ênfase no real, que é diretamente observável, permitindo ao estudante a possibilidade de significados e explicações a essa experiência (GASPAR; MONTEIRO, 2005). Essas atividades, vinculadas a uma postura didática que valoriza os saberes dos estudantes e os possibilita a oportunidade de questionar, opinar e levantar hipóteses, certamente resultará em um processo de ensino-aprendizagem muito mais eficiente. Os autores ainda salientam alguns fatores que favorecem as atividades de demonstração: um único equipamento para todos os alunos, a possibilidade da sua utilização durante a apresentação teórica despertando o interesse e a motivação dos alunos, facilitando assim o processo de aprendizagem. Os artigos classificados nesta categoria são aqueles que sugeriram esse objetivo ou aqueles cujo propósito não está focado na manipulação.

No artigo de Ganci e Ganci (2012) são sugeridos 18 experimentos de demonstração sobre eletrostática utilizando material de baixo custo. Um experimento de demonstração simples feito com material de baixo custo para estudar os meios granulares é encontrado no artigo de López, Vercik e Costa (2008) que ainda inclui propostas experimentais. Uma atividade de demonstração (STEWART, 2007), com material de baixo custo, para descrição de motores homopolares que usa ímãs de neodímio.

Ensino \& Pesquisa, União da Vitória, v. 18, n 1, p. 136-166, jan./abr., 2020. 
Através da demonstração realizada em um aparato experimental simples, composto por dois espelhos planos, Ribeiro (2014b) instiga novos questionamentos sobre a formação de imagens ciclópicas. A refração da luz é explorada no artigo de Turchiello e colaboradores (2016) com um experimento de baixo custo para a constatação experimental de que a luz pode modificar as propriedades ópticas de um meio. Para estudar a difração da luz, Catelli e Libardi (2010) sugerem uma atividade de demonstração usando CDs como redes de difração.

O artigo de Neves (2013) apresenta aparato muito simples de ser construído e de custo quase zero que permite ao professor fazer demonstração sobre a produção de ondas estacionárias em uma corda.

Após a construção de um telescópio de múons, utilizando cintiladores plásticos, os autores sugerem uma demonstração experimental, de Física Moderna, da dilatação do tempo e da contração do espaço dos múons da radiação cósmica (FAUTH et al., 2007). Laganá (2011) sugere o estudo de raios cósmicos através das imagens obtidas com uma câmara de nuvens de baixo custo. Preocupados com o estudo da Física moderna Paranhos, Lopes-Richard e Pizani (2008) desenvolveram uma lâmpada de vapor de mercúrio para atividade demonstração prática, que pode ser usada na introdução do efeito fotoelétrico e outros assuntos da Física moderna.

Santos e colaboradores (2015) apresentam a montagem de um experimento de levitação supercondutora, sugerindo que a demonstração esteja focada no entendimento das propriedades básicas relacionadas ao fenômeno. Rocha e Fraquelli (2004) propõem a demonstração da levitação de um imã repelido por um super condutor.

Para verificar a segunda lei de Newton é descrito um procedimento experimental, que permite acelerar um carrinho sobre um trilho de ar por meio de forças constantes e conhecidas (HESSEL; CANOLA; VOLLET, 2013) mostrando, ainda, como determinar a aceleração a partir de velocidades médias calculadas para intervalos de tempo sucessivos do movimento, usando vários contadores eletrônicos conectados a um único circuito oscilador a cristal. Ribeiro (2014a) elaborou um experimento simples onde é possível visualizar a reflexão total e ainda identificar qual é a superfície refletora.

Em um trabalho que aborda a refração luminosa em recipientes preenchidos parcialmente com água, análise de problemas e proposta experimental, os autores (JUNIOR; JESUS, 2017) apresentaram um trabalho que apresenta uma certa dificuldade na sua classificação. Inicialmente foi feita uma análise sobre as abordagens de alguns livros didáticos de nível médio sobre o fenômeno da refração luminosa, usando a lei de SnellDescartes, os mesmos mostram medidas relacionadas às posições das imagens formadas a partir de um canudo parcialmente imerso em diferentes níveis de água para dois tipos de recipientes: um de base circular e outro retangular.

\section{a.2 Verificação de modelos teóricos}

Hodson (1998) já chamava atenção que não existem experimentos independente de teorias. O mesmo autor ressalta que a experimentação pode ter dois significados: i. testar a adequação empírica da teoria em desenvolvimento e prover evidências retrospectivas para as proposições teóricas; ii. Guiar o desenvolvimento contínuo da teoria na direção da coerência e completude. Borges (2002) ressalta que devemos encontrar formas para que o ensino experimental e o ensino teórico ocorram em concordância, evitando a fragmentação 
do conhecimento. Nessa categoria enquadramos os artigos que trazem como objetivo explicitado a verificação dos modelos teóricos.

Em um desses trabalhos foi analisada a validade da aproximação de lente fina em atividades experimentais que envolvem a determinação de distâncias focais (CARLIN et al., 2007). Utilizando o formalismo matricial para o estudo de trajetórias dos raios luminosos os autores concluíram que para as lentes espessas, comumente utilizadas nos laboratórios didáticos, a aproximação de lente fina não é adequada. Soga, Paiva Jr e Muramatsu (2017) verificaram que uma lente esférica não se comporta como uma lente fina pois sua espessura não é desprezível.

No artigo de Carlin e colaboradores (2009) é apresentado o desenvolvimento de um procedimento experimental para estudar o movimento de elétrons. Inicialmente somente deste movimento ao efeito do campo elétrico, posteriormente ao campo magnético e por fim na presença de dois campos cruzados. Trata-se de um experimento que requer longos períodos de tempo e foi realizado pelos alunos durante 6 aulas de 4 horas cada.

Andrade e colaboradores (2013) apresentam um estudo teórico e experimental do efeito termiônico. Eles utilizaram um dispositivo de baixo custo, usando uma lâmpada de automóvel com dois filamentos independentes que funcionou como uma válvula.

Kovacevic e Simic (2010), usando um dispositivo de gravação de uma placa de som de um computador, conseguiram obter medidas de tempo mais precisas para o estudo do pêndulo simples. Com esta técnica de medição é possível visualizar expectativa teórica e extrair alguns dos valores dos parâmetros a partir dos dados registados como posição, velocidade e aceleração do pêndulo.

No artigo de Lüdke e colaboradores (2013) é apresentado um experimento simples e de baixo custo que possibilita a comprovação de conceitos fundamentais em fenômenos de transporte de energia na forma de calor e a solução da lei de Fourier em coordenadas cilíndricas.

A determinação experimental do coeficiente de atrito de rolamento em um plano inclinado (ANDRADE-NETO; LEYVA-CRUZ, 2015) é apresentada em artigo que mostra ainda a proposta de análise do rolamento de um corpo sobre um plano inclinado.

A Verificação da lei de Boyle através de um arranjo experimental constituído por uma seringa ligada a um manômetro (VERTCHENKO; DICKMAN, 2012) que se baseia apenas nas grandezas que as escalas do arranjo, permitem medir a pressão manométrica e a variação do volume de gás dentro do equipamento. A verificação das lei de BoyleMariotte, Gay-Lussac e a equação dos gases ideais é possível com experimento proposto em (BRUNETTO; CRISTINA; RIBEIRO, 2005).

Ribeiro e colaboradores (2012) sugerem uma atividade experimental que estuda a indução de uma força eletromotriz provocada pelo campo magnético de um solenoide em várias bobinas de prova, colocadas no interior deste. Ela permite analisar a dependência da força eletromotriz induzida com os mais variados fatores experimentais como o número de espiras da bobina de prova, área da secção transversal da bobina de prova, ângulo do eixo da bobina de prova em relação ao eixo do solenoide, frequência angular do sinal gerador e amplitude do sinal de corrente. Pode ser usado para determinar ainda o valor da permeabilidade magnética do vazio e comparar com o valor tabelado. Descrever o fenômeno da indução eletromagnética é o objetivo do artigo de Villalba e colaboradores (2015). Vale ressaltar que os resultados obtidos concordam, levando em conta os intervalos de erro, com as previsões teóricas da Lei de Faraday-Henry. 


\section{a.3 Experimentação investigativa}

Alguns experimentos têm como objetivo desenvolver habilidades básicas de observação ou investigação. Por meio da observação propiciada pelo experimento, os alunos são encorajados a levantar hipóteses e perguntas, e é nesse diálogo, realizado em grupo, que os estudantes aprimoram sua capacidade argumentativa e explicativa. Acrescenta-se ainda, segundo Vygotsky (2001), que no trabalho colaborativo a criança se revela mais forte e mais inteligente do que trabalhando sozinha, para tal ela deve ter liberdade para testar, experimentar e argumentar. Pinho (2000) nos lembra que as atividades experimentais têm o papel de retirar o aluno da passividade e colocá-lo como sujeito ativo na construção do conhecimento. Nessa categoria agrupamos os artigos que tinham como objetivo a investigação, a observação ou que favoreciam a discussão dos modelos teóricos.

No trabalho de Lima, Venceslau e Brasil (2014) é apresentado um experimento simples e de baixo custo que permite ao aluno a investigação, observação e questionamento. Ele mostra, como resultado contra intuitivo, que o princípio de Arquimedes é inadequado para casos em que há contato do corpo com o recipiente. Um artigo que relata a possibilidade de investigar a hidrodinâmica de fluidos incompressíveis utilizando materiais de baixo custo, como garrafas PET (JESUS; JUNIOR, 2011). A proposta didática foi aplicada na parte experimental da disciplina Fluidos e Termodinâmica do curso de Licenciatura em Física do IFRJ - Campus Nilópolis. A aprendizagem da lei de pressão hidrodinâmica de Bernoulli, através da Metodologia: da dissonância à consistência (BARBOSA et al., 2011), foi apresentada em estudo que ocorreu durante 5 semanas, durante o tempo livre dos estudantes e testado após dez semanas. Ele indicou, como resultado, a alta eficiência da metodologia de aprendizagem.

Objetivando a reconceitualização de atividades experimentais, Ribeiro (2015) utiliza um cartum de Gervasio Troche, representando um pai e sua filha caminhando, em que a sombra projetada da menina é maior que a do pai. A imagem foi apresentada a estudantes de óptica no Ensino Médio, que deveriam discutir sua possibilidade Física, além de construir e testar um modelo experimental baseado na figura.

O artigo intitulado "Dinámica del movimiento rotacional: propuesta de experiencias sencillas para facilitar su comprensión" (BERAHA; CARUSELA; EL HASI, 2009) apresenta uma proposta, de fácil realização, que permite articulação entre a abordagem experimental e a discussão dos modelos teóricos analisados no ensino da conservação do estado de movimento rotacional.

Uma metodologia de cunho qualitativo-interpretativo envolvendo doze alunos do primeiro ano do Ensino Médio de um escola pública (LABURÚ; SILVA; SALES, 2010). A pesquisa procura compreender até que ponto os alunos conseguem construir uma aproximação com o conceito científico de medição quando estão envolvidas apenas questões provocativas e experimentos preparados para induzir essa construção.

O artigo de Errobidart e colaboradores (2014) também apresentou uma certa dificuldade de classificação nas nossas categorias, apesar dos autores classificá-lo como de demonstração. Eles utilizaram material de baixo custo para elaborar e construir um dispositivo experimental para estudar qualitativamente os conceitos relacionados a ondas. Eles propõem, ainda, a orientação metodológica ao professor para o uso do dispositivo. A atividade é dividida em 4 procedimentos buscando revisar os conceitos apresentados na 
aula expositiva, porém todo o roteiro é elaborado em forma de perguntas e questionamentos, direcionando o alunos a uma observação investigativa.

Um experimento para descobrir, a partir do espectro de impedância de uma "caixa preta" (montada com resistores e capacitores numa configuração desconhecida), que tipo de associação existe em seu interior é apresentado por seus autores (CHINAGLIA et al., 2008) que utilizam um arranjo experimental composto por um gerador de áudio como fonte AC para alimentar a caixa e um osciloscópio de duplo canal para medir tanto a parte real como a imaginária da impedância complexa do circuito desconhecido em função da frequência do gerador. Em uma outra proposta, a partir de uma bobina automotiva, foi possível a construção e medição de um gerador de ruído eletromagnético (PEROTONI; NUNES; SILVA, 2017).

Catelli e colaboradores (2016) analisaram algumas atividades que se propõem a estudar a Lei da Inércia. Um dos casos analisados é o da folha de papel entre duas garrafas, a partir do qual avaliam se essa demonstração põem de fato a inércia em destaque. Os autores sugerem um procedimento no qual objetos com massas diferentes são usados apresentando estados finais de movimento também diferentes, quando submetidas a forças (aproximadamente) idênticas em intensidade e duração, colocando a Segunda Lei de Newton em evidência.

Um estudo muito interessante de campos elétricos em linhas trifásicas pelo método da cuba eletrolítica foi proposto por Lüdke e Graça (2011). Trata-se de um experimento simples para laboratórios didáticos de eletromagnetismo como material de apoio para a investigação de campos elétricos provenientes de linhas trifásicas, empregando o clássico método da cuba eletrolítica.

Uma análise da experiência de fenda dupla com luz foi realizada pelos autores de um trabalho utilizando conceitos do método de "Soma de vários caminhos" da formulação de Feynman da mecânica quântica (FANARI; ARLEGO; OTERO, 2014).

A proposta de Heidemann, Araujo e Veit (2016) é composta por quatro atividades experimentais (oscilações mecânicas, fluido e termodinâmica) que colocam o aluno como protagonista na investigação do fazer experimental. Os estudantes são postos frente a situações que: i) evidenciam aspectos importantes do processo de modelagem científica, e ii) demandam uma postura ativa.

Visando o estudo das propriedades dos corpos deformáveis, os autores apresentam um trabalho composto por um conjunto de atividades experimentais, para o curso de engenharia, organizadas na forma de uma sequência, em que os alunos exploram, testam e discutem o comportamento de uma borracha tracionada (RAMOS; VERTCHENKO, 2011). O experimento ainda explora a força elástica, acrescentando à lei de Hooke um termo quadrático que permite uma discussão didática dos parâmetros "módulo de Young" e "coeficiente de Poisson".

O artigo sobre Flutuação dos corpos (LONGHINI; NUNES; GRILLO, 2011) é o único destinado ao ensino fundamental. As atividades foram desenvolvidas numa escola privada de Uberlândia/MG com o objetivo de estudar a flutuação dos corpos através de uma metodologia de ensino que privilegiou a problematização, a manipulação de materiais e a interação entre alunos com níveis de conhecimento distintos.

\section{b. Promoção do Desenvolvimento de Conteúdos Procedimentais}

Zabala (1998) denomina como Conteúdo Procedimental o conjunto de ações ordenadas para a realização de um objetivo. Observar, calcular, classificar e inferir são

Ensino \& Pesquisa, União da Vitória, v. 18, nº 1, p. 136-166, jan./abr., 2020. 
alguns exemplos de conteúdos procedimentais. Muitas vezes o objetivo da atividade experimental é desenvolver no aluno esses conteúdos. De modo análogo, Millar e Driver (1987) introduzem algumas habilidades que podem ser relacionados a esses conteúdos: aprender a usar equipamentos e instrumentos específicos, medir grandezas físicas, repetir procedimentos para aumentar a confiabilidade dos resultados, analisar e categorizar os dados obtidos, seja na forma de tabelas, gráficos, esquemas ou diagramas. Coll, Pozo, Saraiba e Valls (1998) enfatizam, ainda, que alguns verbos têm características "procedimentais": manejar, usar, construir, aplicar, coletar, observar, experimentar, elaborar, simular, demonstrar, planejar, compor, avaliar, representar, entre outros, sendo assim, os conteúdos procedimentais são ações que levam o aluno a resolver uma tarefa.

Relacionamos nessa categoria artigos que em sua essência têm objetivos e desenvolvimentos característicos dessas abordagens citadas por esses autores.

Borges, Toniazzo e Silva (2009) defendem que a modelagem matemática de problemas de Física é uma alternativa de ensino que associa a prática e a teoria, e, ainda, que a interpretação dos resultados, construção e aplicação de conceitos e uso de recursos da informática, constituem uma opção metodológica desafiadora no ensino de Física dos dias atuais.

O comportamento oscilatório de um sistema massa-mola é analisado por seus autores (TRIANA; FAJARDO, 2013), em um estudo quantitativo que mostra as diferenças encontradas no valor da frequência angular quando as molas são consideradas ideais (sem massa) e quando se leva em conta a massa efetiva da mola e o amortecimento das oscilações. Em estudo sobre o amortecimento do pêndulo simples, Arnold et al (2011) avaliam a variação da amplitude das oscilações e ajustam os dados obtidos a partir de um modelo matemático.

Em uma metodologia computacional para o estudo dos movimentos (CAVALCANTE; SILVA; PRADO, 2002) é possível foi possível realizar um estudo do coeficiente de restituição em colisões através do espectro sonoro emitido por sucessivos impactos de uma esfera em uma superfície plana.

Cavalcante (2005) propõem um experimento para determinar a constante de Planck utilizando diodos de emissão de luz como sensores espectrais seletivos da radiação emitida por um filamento aquecido, apresentando, ainda, uma proposta para verificação da Lei de Stefan-Boltzmann. A descrição da montagem de um detector Geiger Muller (GM) a partir de um tubo comercial, SBM19 (KAKUNO, 2014) foi realizada em um trabalho no qual também são apresentados resultados de medidas em camisas de lampião, 241Am de um detector de fumaça e de um cinzeiro enriquecido com urânio. A verificação do princípio da incerteza de Heisenberg (ABREGO et al., 2013) é proposta em um artigo que apresenta a montagem do experimento e ainda uma sugestão para o estudo quantitativo. Visando o uso em atividades de ensino de Física experimental de Física moderna a distância, os autores do trabalho elaboraram um sistema de instrumentação virtual (PESSANHA; COZENDEY; SOUZA, 2010).

A conexão entre a Óptica Física e a Óptica Geométrica fica evidenciada no artigo de Cavalcante e Rodrigues (2012). O trabalho propõe um método de ensino de óptica, especialmente de interferência para aulas de Física no Ensino Médio. Observando a interferência entre um feixe advindo diretamente da Fonte e o advindo após uma reflexão especular, os autores realizaram medições do comprimento de onda da luz que resultaram em valores próximos a 700nm, uma concordância razoável com a realidade.

Diodos de emissão de luz são utilizados para o estudo da composição das cores (SANTOS; PEREIRA, 2013). Inicialmente os autores fazem um estudo teórico sobre os

Ensino \& Pesquisa, União da Vitória, v. 18, n 1, p. 136-166, jan./abr., 2020. 
conceitos básicos de calibração radiométrica, fotométrica e colorimétrica de fontes de luz e em seguida apresentam um aparato experimental composto por um circuito de controle de corrente para os LEDs e uma esfera integradora artesanal. Também em trabalho sobre Òptica, os estados de polarização da luz são determinados por meio de medidas de Intensidade luminosa (COSTA, 2002). Para ensinar alguns conceitos de Óptica Física (MÜLLER; FABRIS; CAÇÃO JR., 2003), os autores descrevem um arranjo experimental que pode ser usado na medição da velocidade de um Pêndulo físico, possibilitando a compreensão dos fenômenos de interferência, difração e espalhamento da luz.

A partir de um experimento simples, os autores propõem uma forma de medir a impedância de um cabo coaxial e a velocidade de propagação de um pulso (FONSECA; SANTOS; MONTENEGRO, 2007). Empregando o clássico método do anel de Rowland, Lüdke (2017) discute a implementação de um experimento simples destinado a laboratórios didáticos de eletromagnetismo como material de apoio para a investigação de campos magnéticos e histerese por alunos. Um procedimento experimental para investigar a validade da lei de Faraday (HESSEL; FRESCHI; SANTOS, 2015), a partir da análise dos pulsos induzidos em função da velocidade do imã ao passar pelo centro da bobina é apresentado por seus autores.

Dartora e colaboradores (2014) discutem aspectos teóricos a respeito da permissividade dielétrica e, em seguida, apresentam duas técnicas experimentais: método do circuito $\mathrm{RC}$ e a técnica de refletometria do domínio do tempo para estudá-la.

A utilização do oscilador salino (LAMA; MULATO, 2011) auxilia na compreensão de muitos sistemas biológicos. Foi o que concluíram os autores de um trabalho no qual ele foi utilizado com soluções de sulfato de cobre e cloreto de sódio, alterando parâmetros como o diâmetro e comprimento do capilar, diâmetro do compartimento interno e quantidade de íons indesejados no reservatório principal.

Estudo do Momento de Inércia de uma Placa, através de quatro placas de massa diferentes (PINTÃO; DE SOUZA FILHO, 2002), os autores obtiveram resultados que reforçam a ideia de que o sistema e o procedimento de medida utilizados podem ser uma alternativa para realizar esta prática nos laboratórios de ensino. Em um outro estudo referente ao mesmo tema foi utilizado um cone (PINTÃO; SOUZA FILHO; USIDA, 2005).

Uma técnica para determinação do calor específico em sólidos e líquidos foi proposta por Pereira e colaboradores (2003). Na mesma área de estudo, também foi apresentado um experimento quantitativo para o estudo da transferência de calor (GARCIA et al., 2017) que ocorre durante o resfriamento de um cilindro de aço.

Encontramos também um experimento que explora os conceitos da Óptica Física (MULLER; SILVA; FABRIS, 2005) proporcionando ao estudante a compreensão do fenômeno de interferência e da teoria de Fresnel para a propagação de ondas.

Um estudo comparativo entre as velocidades de rolamento de uma esfera de aço num plano inclinado com lançamento oblíquo (GOYA; LABURÚ; PAULO, 2014) foi apresentado por seus autores, o qual possibilita, ainda, calcular o valor do coeficiente de atrito entre a esfera e o plano inclinado.

Uma sequência de experimentos qualitativos é proposta por Costa, Pietronero e Catunda (2013), onde a complexidade dos circuitos é aumentada gradualmente, e permitem explorar os conceitos fundamentais dos capacitores e circuitos RC. 


\section{c. Processo de Construção do Aparato Experimental}

\section{c. 1 Enfase no uso de tecnologia}

Muitos autores se dedicaram a associar o uso de tecnologias às atividades experimentais. Entre os objetivos estão tornar a obtenção de dados mais eficientes, incorporar objetos do cotidiano dos alunos na sala de aula, entre outros. Encontramos um número significativo de artigos, $10 \%$ do total, que fazem o uso de novas tecnologias. Alguns promovem adaptações de experimentos já conhecidos, utilizando materiais tecnológicos como smartphones e filmadoras digitais. Muitos são utilizados para uma coleta de dados mais precisa, outros utilizam-se de placas Arduino, placas de jogos de computadores, sensores e softwares para criação de novos experimentos ou análise dos dados obtidos. Estas constatações estão de acordo com Araújo e Abib (2003) que salientavam que o emprego de tecnologias modernas está se tornando cada vez mais acessível nos meios educacionais.

Mostrando que a tecnologia, cada vez mais presente em nossas vidas, pode e deve ser inserida no contexto escolar (CORVELONI et al., 2009) propõem a utilização da uma máquina fotográfica digital para analisar o movimento de queda livre. Vertchenko e Vertchenko (2016) também utilizam a máquina fotográfica digital, porém para o estudo de óptica. $\mathrm{O}$ aparato experimental ainda conta com um polarizador removido de um aparelho celular e um monitor LCD de um computador. Dois experimentos de mecânica são analisados empiricamente (SISMANOGLU et al., 2009) utilizando uma filmadora digital associada ao software de domínio público VirtualDub para análise de diversas variáveis dinâmicas.

As placas Arduino estão ganhando um espaço nas atividades experimentais por terem um custo relativamente baixo. Souza e colaboradores (2011) sugerem um estudo sobre o oscilador amortecido e transferência radiativa de calor, com placa Arduino assistida pelo computador. Um experimento de condução térmica usando sensores de temperatura digitais com tecnologia one-wire (AMORIM; DIAS; SOARES, 2015) utiliza uma placa Arduino para controle e aquisição de dados, obtendo resultados suficientemente sensíveis para revelar uma distribuição não linear de temperaturas. Para o ensino de gráficos da cinemática os autores (DWORAKOWSKI et al., 2016) descrevem a construção de um aparato experimental que utiliza o software PLX-DAQ e um sensor sonar de ultrassom acoplado a uma plataforma micro controlada para realizar leituras de posição e distância de objetos. Além da descrição detalhada da construção do aparato experimental, no trabalho é feito um breve relato sobre alguns resultados do seu uso.

Os smartphones, tão utilizados pelos estudantes, podem ser empregados para as atividades experimentais. $\mathrm{O}$ sensor de aceleração de um smartphone pode ser aproveitado para estudar o movimento circular (CASTRO-PALACIO et al., 2014). Jesus e Sasaki (2014) propõem um experimento de baixo custo, incorporando, uma câmera de smartphone e o software livre Tracker para vídeo-análise para o estudo do atrito. Aliando tecnologia aos experimentos Bonventi e Aranha (2015) utilizam a filmagem do experimento com um smartphone e os dados analisados pelo software livre "Tracker", obtendo a função que descreve a oscilação amortecida.

A placa de jogos do computador também pode ser utilizada em atividades experimentais. Um dispositivo de baixo custo para medidas de intervalos de tempo, velocidades e acelerações, variáveis importantes no estudo da mecânica (DIONISIO; 
MAGNO, 2007). O uso da porta joystick com meio de aquisição digital de dados foi a solução para a obtenção de dados de uma experiência sobre a Segunda Lei de Newton (RAMIREZ; CINELLI; IRIGOITE, 2005) permitindo que o aluno focalize sua atenção nos conceito de físicos. A entrada digital da porta de jogos da placa de som, também é utilizada (FIGUEIRA; VEIT, 2004) através da proposta de uso da planilha Excel como instrumento na aquisição e análise de medidas de intervalo de tempo do pêndulo amortecido. Outro experimento usando a porta de jogos de um computador é utilizado para medida e coleta de dados (LAUDARES; LOPES; CRUZ, 2004) mostrando excelentes resultados para o estudo do movimento uniforme e movimento uniformemente variado.

A visualização da radiação infravermelha é demonstrada através de dois experimentos utilizando uma Webcam, devidamente alterada para ser sensível a tal radiação (MICHA et al., 2011).

O uso de um software "Creative Wave Studio" (LUCA; GANCI, 2011) para obter medidas precisas dos períodos de oscilação em torno dos dois diferentes eixos fornecem não apenas uma comprovação convincente das características principais deste exemplo de problema solúvel como também propiciam uma medida da aceleração da gravidade.

Um experimento para o estudo do lançamento horizontal de uma esfera, através de vídeo análise foi apresentado por seus autores (JESUS; SASAKI, 2015). Através da técnica proposta é possível ilustrar a transição do rolamento com deslizamento para o rolamento puro para diferentes ângulos de inclinação inicial analisados.

\section{c. 2 Enfase na utilização de Materiais de Baixo Custo}

Quando a experimentação é realizada com material de baixo custo, ou custo zero, o aluno sente-se livre para manipulá-lo e explorá-lo sem a preocupação de danificar um instrumento caro e complexo, permitindo assim uma maior liberdade despertando, assim, o seu interesse. Autores como Ferreira (1978), defendem a importância da utilização de material de baixo custo para atividades experimentais, propondo que os professores busquem alternativas à ausência de laboratórios bem equipados. Santos, Piassi e Ferreira (2004) argumentam que a familiaridade do aluno com os materiais utilizados (materiais de baixo custo) aproxima o aluno do conhecimento científico, pois mostra que a Física se aplica ao mundo real, além de oportunizar estudante a manipulação e o controle, despertando o interesse e uma atitude mais questionadora.

Damásio e Steffanie (2007) descrevem uma atividade multidisciplinar realizada em uma escola pública da cidade de Criciúma, SC, envolvendo toda comunidade escolar do Ensino Médio na construção de aquecedores solares caseiros com materiais descartáveis.

Peralta e Rego (2016) exploram a utilização de fotodiodos de baixo custo como fotodetectores, apresentando uma discussão dos resultados obtidos com base na distribuição espectral de Planck.

Atividades experimentais sobre Óptica são as que ocorrem com maior incidência no nível médio. Entre elas está um experimento simples e de baixo custo para discutir a natureza ondulatória da luz e o limite em que a óptica geométrica é válida (SOUZA et al., 2015). A compreensão do mecanismo da visão em cores é discutida com base na teoria tri cromática de Young Helmholtz (SILVEIRA; BARTHEM, 2016a), fazendo uso de um diodo emissor de luz tricolor RGB, em uma montagem de custo relativamente baixo. Um projetor de gotas é um experimento didático e de baixo custo (DORTA; SOUSA; MURAMATSU, 2016) que pode ser utilizado em aulas de diferentes disciplinas tanto de exatas como biológicas, em nível de ensino fundamental, médio e superior. Lunazzi e 
Magalhães (2009) propõem uma demonstração na qual a luz difratada por um simples disco digital funciona como um axicon, sua simplicidade torna possível a observação e verificação de um fenômeno pouco explorado em sala de aula.

Em um experimento sobre ondas sonoras, os autores (PEREIRA; SILVA; FEREIRA, 2003) desenvolveram um programa de computador para a geração de áudio visando a determinação da velocidade do som no ar. Eles apresentam ainda roteiros de experimentos que podem ser realizados pelos alunos em casa.

Um aparato experimental construído com material de baixo custo, para realizar diversos experimentos em regime de corrente alternada (AZEVEDO et al., 2017) pode ser usado como uma ferramenta demonstrativa explorando a lei de indução e Faraday. Viana e Arnold (2017) propõem a construção de um circuito eletrônico para medir a impedância elétrica.

Para simular o movimento de rotação de um satélite artificial no espaço, Reis e colaboradores (2008) utilizam latinhas de refrigerante vazias e outros materias de baixo custo. Os conteúdos que podem ser explorados com esse experimente são: terceira lei de Newton, pressão e movimento rotacional de um corpo no espaço.

\section{c.3 Ênfase na Montagem de equipamentos}

Nessa categoria agrupamos 40 artigos, 29,9\% do total de artigos publicados no período pesquisado. Esse expressivo número está de acordo com as afirmações de Pinho (2000) que ressalta que em sua pesquisa sobre publicações referentes a atividades experimentais, na ampla maioria das vezes as publicações oferecem sugestões para construção de novos equipamentos e novas montagens experimentais.

Silva e Leal (2017) apresentam uma proposta de construção de um laboratório de Física utilizando materiais recicláveis. Com os aparatos construídos é possível explorar atividades experimentais nas áreas da Mecânica, Óptica, Eletromagnetismo, Hidrostática, Termologia e Física Moderna.

Após um estudo, com alunos portugueses, sobre o ensino experimental da Física os autores desenvolveram um conjunto de kits experimentais com vários graus de complexidade. No referido trabalho é apresentada uma destas experiências, voltada ao estudo das características de um gerador (pilha voltaica) e de um receptor (voltâmetro). Ele também contempla os resultados dos experimentos após algumas aplicações (OLIVEIRA; PAIXÃO, 2017).

Um indutímetro pode ser construído em laboratório e utilizado para medidas de pequenas indutâncias, possibilitando um estudo quantitativo nos laboratórios didáticos de eletromagnetismo, como mostrado pelo autor (LÜDKE, 2010a). De modo semelhante, a construção de um gaussímetro de baixo custo (MAGNO; ANDRADE; ARAÚJO, 2011) pode ser encontrada em um artigo no qual também é apresentada uma proposta de construção de um sensor de campo magnético utilizando uma sonda de efeito Hall e componentes eletrônicos simples. Além disso, é mostrada a sua aplicação no mapeamento do campo magnético de um par de bobinas de Helmholtz e na comprovação experimental das leis de Ampère, de Faraday e de Gauss para o magnetismo. Robert (2003) mostra uma técnica para o cálculo do campo magnético gerado por uma bobina de Helmholtz em torno de seu centro de simetria. São descritos detalhes experimentais e citados experimentos que podem ser realizados com esta bobina.

Utilizando materiais de baixo custo para reproduzir a Experiência de Oersted em sala de aula (CHAIB; ASSIS, 2007), os autores, além da descrição da montagem

Ensino \& Pesquisa, União da Vitória, v. 18, n 1, p. 136-166, jan./abr., 2020. 
experimental, sugerem os procedimentos que podem ser utilizados para enriquecer as aulas de eletromagnetismo. A construção de um instrumento virtual usando um sistema de aquisição de dados que integra um conhecido software e um método físico particular sobre o estudo de curvas de histerese de fitas magnéticas macias pode ser encontrado no trabalho de Rosa et al, (2016). Lüdke (2012) apresenta detalhes da construção de um capacímetro destinado a medidas de capacitância elétrica de pequenos objetos metálicos próximos entre si.

O estudo sobre a dinâmica de escoamento geofísico é possível com o projeto de construção de uma mesa giratória (MILL; SANTOS; PAIVA, 2015). Os autores apresentam ainda um experimento clássico que pode ser desenvolvido com o equipamento.

Um experimento, com montagem complexa, é proposto por Lüdke e Cauduro (2013) destinado ao ensino de conceitos fundamentais da biofísica da ultrassonografia para fins de diagnóstico hemodinâmico e investigação da circulação arterial.

A utilização de placas Arduino para a aquisição e automação de dados mostra-se muito eficiente e versátil em atividades experimentais. Cavalcante, Tavolaro e Molisani (2011) apresentam, como exemplo de aplicação, o estudo de carga e descarga de um capacitor, fornecendo ainda todos os códigos fontes necessários para a interação com o Arduino, além de links para acesso a tutoriais que possibilitam a reprodução deste e outros experimentos. Voluci e colaboradores (2013) propõem o estudo do fenômeno de queda de um objeto automatizado com a placa Arduino, permitindo a análise e o conhecimento da incerteza de uma medida. Também utilizando uma placa Arduino, Carvalho e Amorim (2014) apresentam uma montagem experimental simples para o estudo da maré atmosférica e as oscilações barométricas, efeitos fundamentalmente de origem térmica devido ao aquecimento da atmosfera produzido pela radiação solar. Apresenta também uma comparação entre a maré atmosférica e o efeito gravitacional da maré oceânica, destacando as diferenças entre os dois fenômenos. O desenvolvimento de um kit experimental com Arduino para o ensino de Física Moderna no Ensino Médio (SILVEIRA; GIRARDI, 2017) apresenta a descrição da construção e do funcionamento de um aparato experimental para demonstrar o efeito fotoelétrico.

Utilizando diodos emissores de luz, Silveira e Barthem (2016b) propõem construir um disco, como o de Newton, no qual é possível compor através dos mesmos não apenas a cor branca, como também a amarela, a ciano e a magenta. Nesse procedimento, as cores são geradas através da síntese aditiva com base na teoria tri cromática de YoungHelmholtz.

O artigo de Souza e Domingues (2016) descreve a construção e o funcionamento de um sistema de aquisição de dados automático de muito baixo custo formado por uma chave óptica (photogate), para uso em medidas de intervalos de tempo. Ainda objetivando medidas de intervalo de tempo encontramos um artigo que apresenta o desenvolvimento de um sistema de baixo custo, baseado em um micro controlador PIC (ANDRADES; SCHIAPPACASSA; SANTOS, 2013), sua aplicação é proposta em um experimento que mostra a medida do período de oscilação de um pêndulo. Hessel e colaboradores (2008) mostraram como montar um contador eletrônico digital de 4 dígitos utilizando componentes de baixo custo e, ainda, como um contador em associação com um cristal oscilador de $1 \mathrm{MHz}$ pode ser utilizado para medir com precisão intervalos de tempo na faixa de microssegundos, décimos de milissegundos e milissegundos. Apresentam ainda 5 aplicações distintas envolvendo medida de frequência, velocidade e aceleração e técnicas eletrônicas para iniciar/interromper automaticamente uma contagem são também discutidos. Um outro artigo que descreve a construção de um aparato de baixo custo para 
medir intervalos de tempo em sólidos rígidos que se movem no trilho e passam através das fotocélulas também foi apresentado por seus autores (MORALES; MORA, 2012). A preocupação sobre a aquisição de dados em laboratórios (CAVALCANTE; BONIZZIA; GOMES, 2008) levou os autores utilizaram a entrada de microfone da placa de som do computador como interface para medir intervalos de tempo em experiências de mecânica. O sistema usa sensores sensíveis à luz, acoplados diretamente na conexão mic da placa de som. A coleta e análise dos sinais gerados pelo bloqueio e desbloqueio de incidência de luz nos fotos sensores são realizadas por intermédio de versões shareware e/ou freeware de programas de análise sonora disponíveis na Internet. O artigo de Hessel e Perinotto (2011) apresenta um método indireto para medir intervalos de tempo baseado na curva de descarga de um capacitor através de um resistor. Objetivando marcar o tempo para atividades experimentais de cinemática (HESSEL et al., 2017), os autores apresentam a construção de um marcador de tempo utilizando um compressor de ar para aquário e uma caneta hidrográfica.

A construção de um aparato experimental, usando material de baixo custo e um software livre LOGO, utilizado na aquisição de dados foi realizada por Soares e Borges (2010) para investigar o conceito de inércia galileano por meio do plano inclinado de Galileu.

Pizetta e Mastelaro (2014) propuseram a construção de um dispositivo com materiais de relativo baixo custo para a determinação do coeficiente de dilatação térmica de diferentes materiais, além de sugerir e mostrar os dados obtidos com a análise de cinco elementos: alumínio, latão, cobre, cimento e vidro. Para determinar o coeficiente de dilatação é necessário uma boa técnica para medir a temperatura final dos corpos, o artigo de Gonçalves e colaboradores (2013) apresenta uma metodologia de medição para aferir a temperatura final dos corpos, mostrando ainda sua aplicação em uma atividade experimental. Silva e Muramatsu (2007) propõem uma técnica para determinar a medida do coeficiente linear de dilatação térmica do alumínio, usando o interferograma obtido a partir da transformada de Fourier sobre a soma de duas imagens de speckle deslocadas.

Para otimizar a diferença de temperatura e fluxo de calor, um tubo R-H é construído usando peças de baixo custo (GARCÍA CONTRERAS; MUÑOZ BRAVO; FAJARDO, 2008), possibilitando, ainda, verificar o efeito que tem que variar alguns de seus parâmetros, tais como: o comprimento do tubo, o diâmetro da saída de ar frio e o diâmetro de uma válvula cilíndrica no gradiente de temperatura gerado nas extremidades.

A construção da câmara anecóica usada para medir a perda de transmissão sonora é indicada em detalhe, usando materiais de baixo custo (PIEDRAHITA; FAJARDO, 2012), exibindo a dependência da perda da transmissão sonora com a densidade e estrutura do material utilizado para atenuar o som. A velocidade do som no ar e efeito Doppler foram explorados em um único experimento (LÜDKE et al., 2012), através dos circuitos de produção e captação de sinais de ultrassons em $40 \mathrm{kHz}$ que permitem, além de determinar a velocidade, explorar o efeito Doppler-Fizeau quantitativamente, o que não pode ser feito com ondas sonoras audíveis. Um sistema experimental para geração e aquisição de dados usando o microfone e sua placa de som foi apresentado pelos autores (MAGNO et al., 2004) que, para demonstrar sua utilidade, estudaram a ressonância de um circuito oscilador RLC. Uma análise dos aparatos experimentais para o estudo de ondas sonoras estacionárias foi apresentada por Pizetta et al (2017). A fim de melhorá-lo, os autores fizeram uma adaptação para que a movimentação do êmbolo e do microfone fossem realizados de forma independente. Uma abordagem teórica e experimental do oscilador harmônico em duas dimensões (PEREIRA et al., 2014), foi apresentada pelos autores do trabalho que, variando 
a frequência da onda, mostraram que é possível estudar as diferentes curvas de Lissajous geradas pelo experimento. Também foi mostrado ser possível verificar tanto a harmonicidade das ondas estacionárias quanto a relação numérica existente entre os harmônicos presentes em oscilações obtidas para um dado modo de excitação (GOMES; LÜDKE, 2011).

A determinação da tensão superficial de líquidos é possível através da construção de uma balança com materiais de baixo custo como a proposta por Reis e colaboradores (2015). O princípio de funcionamento do dispositivo consiste na medida da força necessária para desprender uma lâmina de vidro parcialmente imersa em um líquido. Os valores da tensão superficial são calculados com base nos conceitos de momento de forças, e considera as interações intermoleculares entre a lâmina e a superfície do líquido.

Pedroso e colaboradores (2016) propõem a construção de um instrumento eletrônico denominado luxímetro digital, aliando a simplicidade e o baixo custo. Sugerem ainda atividades que possibilitam várias discussões sobre Óptica e Física Moderna. Para medir a fluorescência, os autores (PAVONI et al., 2014) apresentam um arranjo simples e bastante ilustrativo que utiliza materiais disponíveis em laboratórios, o fluorímetro. Um aparato experimental de baixo custo para possibilitar estudos quantitativos e qualitativos sobre técnicas de espectrofotometria também foi proposto (LÜDKE, 2010b).

A descrição de um sistema fotodetector acessível (GUTIERRE et al., 2017), a partir de um resistor dependente de luz (LDR), o qual é um elemento cuja resposta é não-linear e, por isso, necessita de uma calibração prévia do sistema, foi testado em experiências de quantificação da potência da luz em condições estacionárias.

Uma Oficina de Lunetas, de baixo custo, foi realizada num curso de formação continuada para professores em Baurú - SP (IACHEL et al., 2009). Seu objetivo era complementar os saberes docentes sobre a astronomia.

Abordagem do ensino de aspectos importantes da Física Moderna, através do uso de um laser de xenônio multi-iônico pulsado (GALLARDO; LAQUIDARA; ALMANDOS, 2007), possibilitou abordar aspectos importantes da Física Moderna. O artigo apresenta a montagem do aparato experimental e algumas sugestões de estudos que podem ser realizados.

Serra, Moreno e Magalhães (2010) descrevem um aparato experimental portátil projetado para obter hologramas na escola e em casa. O artigo apresenta a metodologia a ser seguida, os métodos de processamento utilizados para diferentes tipos de emulsões holográficas, uma análise dos defeitos que os hologramas produzidos podem apresentar e a maneira de detectá-los e erradicá-los.

\section{Artigos teóricos}

Relacionamos, por fim, os artigos que discutem o papel e a importância da experimentação no ensino de Física bem como a eficiência das atividades, os benefícios alcançados através das mesmas e demais aspectos teóricos e metodológicos da sua utilização. Nesta categoria selecionamos cinco artigos no período considerado.

Em trabalho intitulado: "Os objetivos do laboratório didático na visão dos alunos do curso de Licenciatura em Física da UNESP-Bauru", Grandini e Grandini (2004) mostraram que, na opinião dos alunos (futuros professores), o laboratório didático vem cumprindo o seu papel, e que estes indicam como benefícios de sua utilização o fato de 
proporcionarem maior contato entre professor e aluno, ensinando princípios e atitudes no trabalho experimental, o aprimoramento da capacidade de observação, utilizando dados experimentais na solução de problemas específicos e, principalmente, estimularem e manterem o interesse dos alunos no ensino de Física.

Pereira e Barros (2010) discutem os resultados de um projeto implementado em 2008 em três turmas, durante 4 meses, no Rio de Janeiro, que resultou na produção de 14 vídeos sobre atividades experimentais. Além da análise realizada sobre os vídeos, embasados no referencial de Nedelsky para o trabalho experimental e de Driver para os aspectos da representação epistemológica dos estudantes, o artigo apresenta um discussão sobre importância do uso de atividades didáticas práticas.

A eficiência relativa de dois métodos de aprendizagem: Ler, Apresentar, Questionar (LAQ) e Experimentação, Discussão (ED), foi avaliada por Marušić e Sliško (2012). O objetivo do trabalho foi de estabelecer princípios para a mudança da atitude negativa dos alunos frente ao ensino de Física. Os autores concluíram que o método ED melhora significativamente a atitude dos alunos frente ao estudo da disciplina.

Afonso e Chaves (2015) analisaram os três volumes da obra Problemas Práticos de Física Elementar, de Heitor Lyra da Silva, editada entre 1916 e 1929, destinada a alunos dos então cursos regulares (primário e secundário) e profissional. O livro se preocupou em trazer propostas experimentais, em quase todos os conteúdos programáticos, que fossem acessíveis a todas as regiões do país. Ele traz uma discussão acerca dos motivos pelos quais ideias inovadoras da educação sob princípios liberais não conseguiram se impor às correntes conservadoras que dominavam o cenário educacional brasileiro, sendo a nova proposta didática relegada ao esquecimento.

Um estudo investigativo para o ensino de espelhos esféricos foi realizado por Sasaki e Jesus (2017). O trabalho foi desenvolvido utilizando uma metodologia de aprendizagem ativa com a estratégia de analogias ponte e conceitos âncora. Os estudantes, quatro turmas distintas de uma escola da rede federal, realizaram dois experimentos referentes às características das imagens formadas por um espelho côncavo. As conclusões do artigo são referentes à relação entre conflito cognitivo e conceitos prévios, e as mudanças que o uso de uma metodologia de aprendizagem ativa que provoque o conflito cognitivo com as analogias ponte podem gerar.

\section{Considerações finais}

As atividades experimentais são reconhecidas no meio acadêmico como importantes facilitadoras da aprendizagem, sobretudo na área de ciências. As realizações de atividades nas quais os alunos utilizam instrumentos e materiais concretos com diferentes objetivos, a partir de planejamentos elaborados previamente, têm sido relatadas e são consideradas por inúmeros autores como das mais relevantes para o ensino de disciplinas como a Física. A importância dessas atividades são destacadas em diversos trabalhos que se dedicam a identificar formas de realização das mesmas, a utilização dos planejamentos e dos recursos disponíveis nas diferentes escolas.

Ao analisarmos as publicações ao longo dos anos, percebeu-se um aumento significativo no número de trabalhos que abordavam o tema atividades experimentais. Isso demonstra uma preocupação crescente dos professos em variar os recursos didáticos, buscando motivar os alunos ao ensino de Física. Isso está de acordo com o que afirma Shulman e Tamir (1988) que, ao justificarem a importância do uso do laboratório no

Ensino \& Pesquisa, União da Vitória, v. 18, n 1, p. 136-166, jan./abr., 2020. 
ensino de ciências, enumeram diversos benefícios, entre eles o de despertar e manter interesse, atitude, satisfação, mente aberta e curiosidade na Ciência.

Ao realizarmos uma classificação e uma exposição, mesmo que sucinta, dos artigos apresentados durante um período de 16 anos, produzimos um trabalho que esperamos que possa se tornar uma fonte de consulta para os docentes que desejam inserir atividades experimentais como mais um recurso didático em sua prática docente. A análise que realizamos expõem um panorama das publicações sobre atividades experimentais em um periódico de grande inserção e relevância para os profissionais da área.

Ressalvadas algumas diferenças nas abordagens realizadas, considerando conjuntamente o nosso trabalho e a pesquisa realizada por Abib e Araújo (2003) obtém-se uma visão das publicações sobre atividades experimentais na Revista Brasileira no Ensino de Física no período compreendido entre 1991 e 2017. Verificando-se que, ao longo dos anos, tem ocorrido um aumento significativo no número de publicações e uma melhor distribuição temática, porém, verifica-se um aumento desproporcional das publicações relativamente ao nível de ensino, uma vez que os trabalhos passaram a se dedicar mais ao ensino superior em detrimento daqueles dedicados ao ensino médio.

Nossa revisão evidencia com clareza uma carência de relatos sobre atividades experimentais realizadas no Ensino Fundamental e Médio, o que pode indicar uma menor utilização dessa estratégia de ensino por parte dos professores desses níveis, ou apenas a falta de hábito dos mesmos em desenvolverem e divulgarem pesquisas referentes à sua prática docente.

A grande maioria dos artigos sobre atividades experimentais discorre sobre técnicas de construção de novos aparatos, muitos deles para obtenção de medidas mais precisas. Essa preocupação dos professores em elaborar, improvisar, adaptar materiais e atividades experimentais mesmo em condições adversas, muitas vezes tendo que recorrer a materiais de baixo custo, demonstra a importância que esses docentes dão às mesmas, além de demonstrar o cuidado e a dedicação com que se dedicam em incorporar novas propostas e ações visando uma aprendizagem mais eficiente nas suas disciplinas.

\section{Referências}

ABREGO, B. et al. Montagem de um conjunto experimental destinado à verificação do princípio da incerteza de Heisenberg. Revista Brasileira de Ensino de Fisica, v. 35, $n^{0} 3$, 2013.

AFONSO, J. C.; CHAVES, F. A. B. Uma proposta inovadora de ensino de física experimental no início do Século XX. Revista Brasileira de Ensino de Física, v. 37, n. 1, p. 1601, 2015.

ALVES FILHO, J. DE P. ATIVIDADES EXPERIMENTAIS: DO MÉTODO À

PRÁTICA CONSTRUTIVISTA. [s.1.] Universidade Federal de Santa Catarina, 2000. AMORIM, H. S. DO; DIAS, M. A.; SOARES, V. Sensores digitais de temperatura com tecnologia one-wire: Um exemplo de aplicação didática na área de condução térmica.

Revista Brasileira de Ensino de Física, v. 37, no 4, p. 4310-4319, 2015.

ANDRADE-NETO, A. V.; LEYVA-CRUZ, J. A. Análise teórica e proposta para determinação experimental do coeficiente de atrito de rolamento em um plano inclinado.

Revista Brasileira de Ensino de Física, v. 37, nº 4, p. 4303, 2015.

ANDRADE, N. S. DE et al. Investigação teórica e experimental do efeito termiônico.

Revista Brasileira de Ensino de Física, v. 35, $\mathrm{n}^{\mathrm{0}}$ 1, 2013. 
ANDRADES, J. C.; SCHIAPPACASSA, A.; SANTOS, P. F. Desenvolvimento de um periodímetro microcontrolado para aplicações em física experimental. Revista Brasileira de Ensino de Física, v. 35, n. 2, p. 2503-2-2503-11, 2013.

ARAÚJO, M. S. T. DE; ABIB, M. L. V. D. S. Atividades experimentais no ensino de física: diferentes enfoques, diferentes finalidades. Revista Brasileira de Ensino de Física, v. 25, n. 2, p. 176-194, 2003.

AUSUBEL, D. P. Educational Psychology. New York: Holt, Reinchart \& Winston, 1968. AZEVEDO, G. T. DE et al. Gerador trifásico de baixo custo para o ensino de física.

Revista Brasileira de Ensino de Fisica, v. 39, n 3, 2017.

BARBOSA, L. H. et al. El Soplador mágico: un experimento discrepante en el aprendizaje de la ley de presión hidrodinámica de Bernoulli. Revista Brasileira de Ensino de Física, v. 33, n. 4, p. 4309-4309, 2011.

BERAHA, N.; CARUSELA, M. F.; EL HASI, C. D. Dinámica del movimiento rotacional: propuesta de experiencias sencillas para facilitar su comprensión. Revista Brasileira de Ensino de Física, v. 31, n ${ }^{0}$ 4, 2009.

BONVENTI JR., W.; ARANHA, N. Estudo das oscilações amortecidas de um pêndulo físico com o auxílio do "Tracker". Revista Brasileira de Ensino de Física, v. 37, n” 2,2, p. 2504-2509, 2015.

BORGES, A. T. Novos rumos para o laboratório escolar de ciências. p. 2-11, 2002.

BORGES, P. A. P.; TONIAZZO, N. A.; SILVA, J. C. Equilíbrio no espaço:

experimentação e modelagem matemática. Revista Brasileira de Ensino de Física, v. 31, $\mathrm{n}^{\mathrm{o}} 2,2009$.

BRASIL. Plano Nacional de Pós-Graduação 2005-2010. Brasilia: MEC/Capes, 2005. BRUNETTO, R. S.; CRISTINA, A.; RIBEIRO, M. Equipamento experimental para determinação de dados pVt para sistemas gasosos. Revista Brasileira de Ensino de Física, v. 27, $\mathrm{n}^{\mathrm{o}}$ 3, p. 363-367, 2005.

CARLIN, N. et al. A aproximação de lente fina é sempre válida em experimentos para determinação de distâncias focais? Revista Brasileira de Ensino de Física, v. 29, nº 2, p. 299-304, 2007.

CARLIN, N. et al. Estudo experimental do movimento de partículas carregadas em campos etricos e magnéticos : seletor de velocidades. Revista Brasileira de Ensino de Física, v. 31, n. n. 2, p. 2308, 2009.

CARVALHO, L. R. M. DE; AMORIM, H. S. DE. Observando as marés atmosféricas: uma aplicação da placa Arduino com sensores de pressão barométrica e temperatura. Revista Brasileira de Ensino de Física, v. 36, n. 3, p. 1-7, 2014.

CASTRO-PALACIO, J. C. et al. Using a smartphone acceleration sensor to study uniform and uniformly accelerated circular motions. Revista Brasileira de Ensino de Física, v. 36, n. 2, p. 22-26, 2014.

CATELLI, F. et al. "Demonstração" da lei da inércia? Revista Brasileira de Ensino de Física, v. 38, n. 4, 2016.

CATELLI, F.; LIBARDI, H. CDs como lentes difrativas. Revista Brasileira de Ensino de Física, v. 32, n. 2, p. 2307, 2010.

CAVALCANTE, M. A. Corpo negro e determinação experimental da constante de Planck.

Revista Brasileira de Ensino de Física, v. 27, n³ 3, p. 343-348, 2005.

CAVALCANTE, M. A.; BONIZZIA, A.; GOMES, L. C. P. Aquisição de dados em laboratórios de física: um método simples, fácil e de baixo custo para experimentos em mecânica. Revista Brasileira de Ensino de Física, v. 30, n. 2, p. 2501.1-2501.6, 2008. CAVALCANTE, M. A.; SILVA, E. DA; PRADO, R. DO. O Estudo de Colisões através 
do Som. Revista Brasileira de Ensino de Fisica, v. 24, p. 150-157, 2002.

CAVALCANTE, M. A.; TAVOLARO, C. R. C.; MOLISANI, E. Física com Arduino para iniciantes. Revista Brasileira de Ensino de Física, v. 33, n. 4, p. 4503-4503, 2011.

CAVALCANTE, M. DE A.; RODRIGUES, E. DA S. Uso do "Espelho de Lloyd" como método de ensino de óptica no Ensino Médio. Revista Brasileira de Ensino de Física, v. 34, n. 4, p. 1-4, 2012.

CHAIB, J. P. M. C.; ASSIS, A. K. T. Experiência de Oersted em sala de aula. Revista Brasileira de Ensino de Física, v. 29, n. 1, p. 41-51, 2007.

CHINAGLIA, D. L. et al. Espectroscopia de impedância no laboratório de ensino. Revista Brasileira de Ensino de Física, v. 30, n. 4, p. 4504, 2008.

COLL, C. et al. Os conteúdos na Reforma. $1^{\text {a }}$ edição ed. Porto Alegre: ARTMED, 1998. COLUCI, V. R. et al. Ilustração de incertezas em medidas utilizando experimentos de queda livre. Revista Brasileira de Ensino de Física, v. 35, n. 2, 2013.

CORVELONI, E. P. M. et al. Utilização de máquina fotográfica digital (multi-burst) para aulas experimentais de cinemática - queda livre. Revista Brasileira de Ensino de Física, v. 31, $\mathrm{n}^{\mathrm{o}} 3,2009$.

COSTA, G. G. G.; PIETRONERO, R. C.; CATUNDA, T. Experimentos com supercapacitores e lâmpadas. Revista Brasileira de Ensino de Física, v. 35, n. 1, p. 0106, 2013.

COSTA, E. V. Medidas de Intensidade Luminosa. Polarização. Revista Brasileira de Ensino de Física, v. 24, p. 37-40, 2002.

DAMASIO, F.; STEFFANI, M. H. Ensinando física com consciência ecológica e com materiais descartáveis. Revista Brasileira de Ensino de Física, v. 29, nº4, p. 593-597, 2007.

DARTORA, C. A. et al. Caracterização experimental da permissividade dielétrica de materiais através da técnica de refletometria no domínio do tempo. Revista Brasileira de Ensino de Física, v. 37, n. 1315, p. 1-5, 2014.

DIONISIO, G.; MAGNO, W. C. Photogate de baixo custo com a porta de jogos do PC.

Revista Brasileira de Ensino de Física, v. 29, n. n. 2, p. 287-293, 2007.

DORTA, M. P.; SOUSA, E. C. P. DE; MURAMATSU, M. O projetor de gotas e suas diversas abordagens interdisciplinares no Ensino de Física. Revista Brasileira de Ensino de Física, v. 38, n. 4, p. e4503-2-4503-9, 2016.

DWORAKOWSKI, L. A. et al. Uso da plataforma Arduino e do software PLX-DAQ para construção de gráficos de movimento em tempo real. Revista Brasileira de Ensino de Física, v. 38, n. 3, 2016.

ERROBIDART, H. A. et al. Ouvido mecânico: um dispositivo experimental para o estudo da propagação e transmissão de uma onda sonora. Revista Brasileira de Ensino de Física, v. 36, n. 1, p. 1507, 2014.

FANARI, M. DE LOS Á.; ARLEGO, M.; OTERO, R. The double slit experience with light from the point of view of Feynman's sum of multiple paths. Revista Brasileira de Ensino de Física, v. 36, n. n. 2, p. 2308, 2014.

FAUTH, A. C. et al. Demonstração experimental da dilatação do tempo e da contração do espaço dos múons da radiação cósmica. Revista Brasileira de Ensino de Física, v. 29, n. 4, p. 585-591, 2007.

FERREIRA, N. C. Proposta de Laboratório para a escola brasileira - Um ensaio sobre a instrumentalização no ensino médio de Física. [s.1.] Universidade de São Paulo, 1978. FIGUEIRA, J. S.; VEIT, E. A. Usando o Excel para medidas de intervalo de tempo no laboratório de Física. Revista Brasileira de Ensino de Fisica, v. 26, nº 3, p. 203-211, 
2004.

FONSECA, P.; SANTOS, A. C. F.; MONTENEGRO, E. C. A very simple way to measure coaxial cable impedance. Revista Brasileira de Ensino de Fisica, v. 29, n. 3, p. 373-375, 2007.

GALLARDO, M.; LAQUIDARA, A. P.; ALMANDOS, J. R. Abordaje de la enseñanza de aspectos importantes de la física moderna a traves del uso de un laser de xenon multiionico pulsado. Revista Brasileira de Ensino de Física, v. 29, nº 4, p. 535-542, 2007. GANCI, A.; GANCI, S. Demonstration experiments in electrostatics: low cost devices.

Revista Brasileira de Ensino de Física, v. 34, n 2, p. 1-14, 2012.

GARCÍA CONTRERAS, O. J.; MUÑOZ BRAVO, J. E.; FAJARDO, F. Construcción y caracterización de un tubo Ranque-Hilsch. Revista Brasileira de Ensino de Física, v. 30, n. 4, p. 4305, 2008.

GARCIA, R. L. et al. Resfriamento de um cilindro de aço: estudo experimental da convecção e radiação do calor. Revista Brasileira de Ensino de Física, v. 39, nº 4, 2017. GASPAR, A.; MONTEIRO, I. C. DE C. Atividades experimentais de demontrações em sala de aula: Uma análise segundo o referencial da teoria de Vygotsky. Investigações em Ensino de Ciências, v. 10, $\mathrm{n}^{\circ}$ 2, p. 227-254, 2005.

GIL, A. C. Como elaborar projetos de pesquisa. $6^{\text {a }}$ edição ed. São Paulo: Atlas, 2017. GOMES, C. A.; LÜDKE, E. Uso da ressonância em cordas para ensino de física. Revista Brasileira de Ensino de Física, v. 33, no 3, p. 1-5, 2011.

GONÇALVES, B. et al. Nova metodologia para aferição da temperatura final de hastes metálicas em um experimento de dilatação térmica linear. Revista Brasileira de Ensino de Fisica, v. 35, $\mathrm{n}^{\mathrm{o}} 2,2013$.

GOYA, A.; LABURÚ, C. E.; PAULO, S. Estudo comparativo de rolamento e a determinação do inicio de deslizamento de uma esfera num plano inclinado. Revista Brasileira de Ensino de Física, v. 36, n. 2, p. 2502, 2014.

GRANDINI, A.; GRANDINI, C. R. Os objetivos do laboratório didático na visão dos alunos do curso de Licenciatura em Física da UNESP-Bauru. Revista Brasileira de Ensino de Fisica, v. 26, no 3, p. 251-256, 2004.

GUTIERRE, H. G. et al. Sistema fotodetector econômico para utilização em laboratórios de ensino e pesquisa. Revista Brasileira de Ensino de Física, v. 39, nº 3, 2017.

HEIDEMANN, L. A.; ARAUJO, I. S.; VEIT, E. A. Atividades experimentais com enfoque no processo de modelagem científica: uma alternativa para a ressignificação das aulas de laboratório em cursos de graduação em física. Revista Brasileira de Ensino de Física, v. 38, n. 1, p. 1504, 2016.

HESSEL, R. et al. Contadores eletrônicos no laboratório didático Parte I. Montagem e aplicações. Revista Brasileira de Ensino de Física, v. 30, nº 1, p. 4901, 2008.

HESSEL, R. et al. Uso de um compressor de ar para aquário como marcador de tempo em experimentos de cinemática. Revista Brasileira de Ensino de Física, v. 39, nº 3, p. 1-11, 2017.

HESSEL, R.; CANOLA, S. R.; VOLLET, D. R. An experimental verification of Newton's second law. Revista Brasileira de Ensino de Fisica, v. 35, no 2, p. 2504, 2013.

HESSEL, R.; FRESCHI, A. A.; SANTOS, F. J. DOS. Lei de indução de Faraday: Uma verificação experimental. Revista Brasileira de Ensino de Física, v. 37, n. 1, 2015. HESSEL, R.; PERINOTTO, Â. C. Usando um voltímetro para medir tempo. Revista Brasileira de Ensino de Física, v. 33, n. 4, p. 4316-4316, 2011.

HODSON, D. Experimentos na ciência e no ensino de ciências (TRADUÇÃO). Education philosophy and theory, v. 20, p. 53-66, 1988. 
HODSON, D. Teaching And Learning Science: Towards a Personalized Approach. $1^{\mathrm{a}}$ ed. UK: McGraw-Education, 1998.

HOLTON, G. The Project Physics Course, Then and Now. n. November 2001, p. 779786, 2003.

IACHEL, G. et al. A montagem e a utilização de lunetas de baixo custo como experiência motivadora ao ensino de astronomia. Revista Brasileira de Ensino de Física, v. 31, n. 4, p. 4502-4508, 2009.

IFUSP. Projeto de Ensino de Física. Rio de Janeiro: Instituto de Física da Universidade de São Paulo - FENAME, 1980.

JESUS, V. L. B. DE; JUNIOR, M. A. V. M. Uma discussão sobre hidrodinâmica utilizando garrafas PET. v. 33, $\mathrm{n}^{0}$ 1, p. 1-8, 2011.

JESUS, V. L. B. DE; SASAKI, D. G. G. Video-análise de um experimento de baixo custo sobre atrito cinético e atrito de rolamento. Revista Brasileira de Ensino de Física, v. 36, n. 3, p. 3503, 2014.

JESUS, V. L. B. DE; SASAKI, D. G. G. O experimento didático do lançamento horizontal de uma esfera: Um estudo por videoanálise. Revista Brasileira de Ensino de Física, v. 37, $\mathrm{n}^{\mathrm{o}} 1$, p. 1-8, 2015.

JUNIOR, M. A. V. M.; JESUS, V. L. B. DE. Refração luminosa em recipientes preenchidos parcialmente com água: análise de problemas e proposta experimental.

Revista Brasileira de Ensino de Física, v. 39, nº 3, 2017.

KAKUNO, E. M. Montagem e teste de detector Geiger Muller usando tubo SBM19.

Revista Brasileira de Ensino de Física, v. 36, n. n. 1, p. 1315, 2014.

KOVACEVIC, M. S.; SIMIC, S. Plastic optical fiber as a tool for experimenting with simple pendulum. Revista Brasileira de Ensino de Física, v. 32, n. n. 3, 2010.

LABURÚ, C. E. Fundamentos Para Um Experimento Cativante. Caderno Brasileiro de

Ensino de Física, v. 23, n. 3, p. 382-404, 2006.

LABURÚ, C. E.; SILVA, O. H. M. DA; SALES, D. R. Superações conceituais de estudantes do ensino médio em medição a partir de questionamentos de uma situação experimental problemática. Revista Brasileira de Ensino de Física, v. 32, nº 1, p. 1-15, 2010.

LAGANÁ, C. Estudo de raios cósmicos utilizando uma câmara de nuvens de baixo custo.

Revista Brasileira de Ensino de Fisica, v. 33, nº 3, 2011.

LAMA, L. S. DEL; MULATO, M. Saline oscillator as a teaching experiment. Revista Brasileira de Ensino de Física, v. 33, n. 4, p. 4310-4310, 2011.

LAUDARES, F.; LOPES, M. C. S. M.; CRUZ, F. A. O. Usando sensores magnéticos em um trilho de ar. Revista Brasileira de Ensino de Fisica, v. 26, no 3, p. 233-236, 2004. LIMA, F.; VENCESLAU, G.; BRASIL, G. A downward buoyant force experiment.

Revista Brasileira de Ensino de Física, v. 2309, p. 2-6, 2014.

LONGHINI, M. D.; NUNES, M. B. T.; GRILLO, G. A. Flutuação dos corpos: elementos para a discussão sobre sua aprendizagem em alunos dos anos iniciais do Ensino

Fundamental. Revista Brasileira de Ensino de Física, v. 33, nº 3, 2011.

LÓPEZ, J.; VERCIK, A.; COSTA, E. J. X. Meios granulares e experimentos simples para a sala de aula. Revista Brasileira de Ensino de Física, v. 30, n. 1, p. 1308-1312, 2008.

LUCA, R. DE; GANCI, S. A measurement of $g$ with a ring pendulum. Revista Brasileira de Ensino de Física, v. 33, n. n. 3, p. 3301, 2011.

LÜDKE, E. Um indutímetro para laboratório didático de eletromagnetismo. Revista

Brasileira de Ensino de Física, v. 32, n. 1, p. 1505, 2010a.

LÜDKE, E. Um espectrofotômetro de baixo custo para laboratórios de ensino: aplicações

Ensino \& Pesquisa, União da Vitória, v. 18, n 1, p. 136-166, jan./abr., 2020. 
no ensino da absorção eletrônica e emissão de fluorescência. Revista Brasileira de Ensino de Física, v. 32, $\mathrm{n}^{\mathrm{o}}$, n. 1, p. 1505, $2010 \mathrm{~b}$.

LÜDKE, E. Um método para experimentação com baixas capacitâncias. Revista

Brasileira de Ensino de Física, v. 34, no 3, 2012.

LÜDKE, E. et al. Velocidade do som no ar e efeito Doppler em um único experimento.

Revista Brasileira de Ensino de Física, v. 34, n. 1, p. 1-4, 2012.

LÜDKE, E. et al. Um experimento para ensino de conceitos de transferência de calor em

laboratório de física. Revista Brasileira de Ensino de Física, v. 35, n. 1, p. 1503-1506, 2013.

LÜDKE, E. Estudando Campos Magnéticos e histerese com um anel de Rowland. Revista Brasileira de Ensino de Física, v. 32, n. 1, p. 221, 2017.

LÜDKE, E.; CAUDURO, P. J. Um experimento hemodinâmico em sala de aula para ensino de biofísica da circulação. Revista Brasileira de Ensino de Física, v. 35, n. 3, p. $1-5,2013$.

LÜDKE, E.; GRAÇA, C. O. Estudando campos elétricos de linhas trifásicas pelo método da cuba eletrolítica. Revista Brasileira de Ensino de Física, v. 33, n. 1, p. 1-3, 2011. LUIZ, F. F.; SOUZA, LUIZ EDUARDO S DOMINGUES, P. H. Um sistema automático de baixo custo para medidas de intervalos de tempo. Revista Brasileira de Ensino de Física, v. 38, $\mathrm{n}^{\mathrm{O}}$ 2,e, 2016.

LUNAZZI, J. J.; MAGALHÃES, D. S. F. Fazendo imagens com um simples elemento difrativo ou refrativo: o axicon. Revista Brasileira de Ensino de Física, v. 31, n ${ }^{\mathrm{o}}$ 2, p. 2051, 2009.

M. MÜLLER, J. L.; FABRIS, F.; CAÇÃO JR., E. Um Experimento para Medir Velocidades como Instrumento Motivador no Aprendizado de Conceitos da Ótica Física.

Revista Brasileira de Ensino de Física, v. 25, n. 3, p. 273-277, 2003.

MAGNO, W. C. et al. Realizando experimentos didáticos com o sistema de som de um PC. Revista Brasileira de Ensino de Física, v. 26, nº 1, p. 117-123, 2004.

MAGNO, W. C.; ANDRADE, M.; ARAÚJO, A. E. P. DE. Construção de um gaussímetro de baixo custo. Revista Brasileira de Ensino de Física, v. 32, nº 3, p. 1-8, 2011.

MARUŠIĆ, M.; SLIŠKO, J. Many high-school students don't want to study physics: active learning experiences can change this negative attitude! Revista Brasileira de Ensino de Física, v. 34, n. 3, p. 1-11, 2012.

MICHA, D. N. et al. "Vendo o invisível". Experimentos de visualização do infravermelho feitos com materiais simples e de baixo custo. Revista Brasileira de Ensino de Física, v. 33, n. 1, p. 01-06, 2011.

MILL, G. N.; SANTOS, V.; PAIVA, A. D. M. Projeto de uma mesa giratória para simulação de escoamentos geofísicos. Revista Brasileira de Ensino de Física, v. 37, n. 4, p. $4302,2015$.

MILLAR, R.; DRIVER, R. Beyond processes. Studies in Science Education, v. 14, p. $33-$ 62, 1987.

MORALES, C. A. C.; MORA, C. Experimentos de mecánica con temporizador de bajo costo. Revista Brasileira de Ensino de Física, v. 34, nº 4, 2012.

MOREIRA, M. A.; LEVANDOWISK, C. E. Diferentes Abordagens ao Ensino de Laboratório. Porto Alegre: Editora da UFRGS, 1983.

MULLER, M.; SILVA, J. C. C. DA; FABRIS, J. L. Um experimento simples usado na produção de placas de zonas de Fresnel. Revista Brasileira de Ensino de Fisica, v. 27, $\mathrm{n}^{\mathrm{o}}$ 4, p. 603-608, 2005.

NEVES, U. M. Ensinando sobre ondas transversais, ondas estacionárias e ondas 
polarizadas utilizando um simples motor a pilha. Revista Brasileira de Ensino de Fisica, v. $35, \mathrm{n}^{\mathrm{o}} 1$, p. $2-3,2013$.

OLIVEIRA, F.; PAIXÃO, J. A. Atividade experimental "hands-on" para o estudo das características de um gerador (pilha voltaica) e de um recetor (voltâmetro) com material simples, de fácil acesso e baixo custo. Revista Brasileira de Ensino de Física, v. 39, $\mathrm{n}^{\circ} 1$, e, p. 1-13, 2017.

OLIVEIRA, J. F. D. E. Pós-Graduação no Brasil : do Regime Militar aos dias atuais. p. 351-376, 1968.

PARANHOS, R. R. G.; LOPEZ-RICHARD, V.; PIZANI, P. S. Lâmpada de Hg para experimentos e demonstrações de física moderna: introdução ao efeito fotoelétrico e outros tópicos. Revista Brasileira de Ensino de Física, v. 30, n. 4, p. 4502-6, 2008.

PAVONI, J. F. et al. Uma montagem experimental para a medida de fluorescencia. v. 36, $\mathrm{n}^{\circ} 4,2014$.

PEDROSO, L. S. et al. Construção de um luxímetro de baixo custo. Revista Brasileira de Ensino de Física, v. 38, p. 1-8, 2016.

PERALTA, L.; REGO, F. Deteção da radiação térmica emitida por um filamento de tungstênio aquecido. Revista Brasileira de Ensino de Fisica, v. 38, n ${ }^{\circ}$ 1, p. 1-6, 2016.

PEREIRA, O. C. N. et al. Uma abordagem teórica e experimental do oscilador harmônico em duas dimensões utilizando curvas de Lissajous. Revista Brasileira de Ensino de Física, v. 36, $\mathrm{n}^{\mathrm{0}}$ 2, 2014.

PEREIRA, W. et al. Medida de Calor Específico e Lei de Resfriamento de Newton: Um Refinamento na Análise dos Dados Experimentais. Revista Brasileira de Ensino de Fisica, v. 25, $\mathrm{n}^{\circ}$ 4, p. 392-398, 2003.

PEROTONI, M. B.; NUNES, S.; SILVA, N. Construction and measurement of an electromagnetic noise generator based on an automotive coil. Revista Brasileira de Ensino de Fisica, v. 39, no 4, p. e4310, 2017.

PESSANHA, M. C. R.; COZENDEY, S. G.; SOUZA, M. D. O. Desenvolvimento de uma ferramenta para o ensino de física experimental a distância. Revista Brasileira de Ensino de Física, v. 32, n. 4, p. 4503-1-4503-10, 2010.

PIEDRAHITA, Y.; FAJARDO, F. Construcción de una cámara anecoica para la caracterización de la pérdida de transmisión sonora. Revista Brasileira de Ensino de Física, v. 34, n. 4, p. 9, 2012.

PINTÃO, C. A. F.; DE SOUZA FILHO, M. P. Estudo Experimental do Momento de Inércia de uma Placa. Revista Brasileira de Ensino de Física, v. 24, nº 4, p. 455-459, 2002.

PINTÃO, C. A. F.; SOUZA FILHO, M. P. DE; USIDA, W. F. Estudo experimental do momento de inércia de um cone. Revista Brasileira de Ensino de Fisica, v. 27, nº2, p. 237-243, 2005.

PIZETTA, D. C.; MASTELARO, V. R. Construção de um dilatômetro e determinação do coefiente de dilatação térmica linear. Revista Brasileira de Ensino de Física, v. 36, n. 1, p. 1313, 2014.

RAMIREZ, A. R. G.; CINELLI, M. J.; IRIGOITE, A. M. Automação para obtenção de dados de uma experiência de Física: $2^{\text {a }}$ Lei de Newton. Revista Brasileira de Ensino de Fisica, v. 27, $\mathrm{n}^{\mathrm{o}}$ 4, p. 609-612, 2005.

RAMOS, T. C.; VERTCHENKO, L. Uma abordagem experimental das propriedades dos corpos deformáveis no ensino de física geral para os cursos de engenharia. Revista

Brasileira de Ensino de Física, v. 33, n. 1, p. 01-09, 2011.

REIS, N. T. O. et al. Análise da dinâmica de rotação de um satélite artificial: uma oficina 
pedagógica em educação espacial. Revista Brasileira de Ensino de Física, v. 30, n ${ }^{0} 1$, 2008.

REIS, T. O. et al. Construção de uma balança simples para determinação da tensão superficial de líquidos. Revista Brasileira de Ensino de Física, v. 37, n. 1, p. 1503-1507, 2015.

RIBEIRO, D. T.; ALMEIDA, A. M.; CARVALHO, P. S. Indução eletromagnética em laboratório. Revista Brasileira de Ensino de Física, v. 34, nº 4, 2012.

RIBEIRO, J. L. P. Internal reflection on a watch glass surrounded by water : A simple experiment and a variation. Revista Brasileira de Ensino de Física, v. 36, n 2, p. 7-9, 2014a.

RIBEIRO, J. L. P.; VERDEAUX, M. F. S. Atividades experimentais no ensino de óptica: uma revisão. Revista Brasileira de Ensino de Física, v. 34, n. 4, p. 4403, 2012.

RIBEIRO, P. Construção geométrica e demonstração experimental da formação da "imagem ciclópica" em uma associa çãode dois espelhos planos. Revista Brasileira de Ensino de Fisica, v. 36, $\mathrm{n}^{\mathrm{o}} 4,4,2014 \mathrm{~b}$.

RIBEIRO, P. Uma atividade experimental sobre sombras inspirada em um cartum. Revista Brasileira de Ensino de Física, v. 37, nº 3, 2015.

ROBERT, R. Bobina de Helmholtz. Revista Brasileira de Ensino de Física, v. 25, nº 1, p. 40-44, 2003.

ROCHA, F. S. DA; FRAQUELLI, H. A. Roteiro para a experiência de levitação de um imã repelido por um supercondutor no Ensino de Física. Revista Brasileira de Ensino de Fisica, v. 26, n1, p. 11-18, 2004.

ROSA, P. F. O. et al. Desenvolvimento de instrumentos virtuais para obtenção e caracterização de propriedades físicas. Revista Brasileira de Ensino de Física, v. 38, n. 1, p. 1-8, 2016.

SANTOS, A. L. DOS et al. Experimento demonstrativo de levitação supercondutora: Ferramenta para problematização de conceitos físicos. Revista Brasileira de Ensino de Física, v. 37, n. 2, p. 2505-1-2505-8, 2015.

SANTOS, E. I. DOS; PIASSI, L. P. DE C.; FERREIRA, N. C. Atividades Experimentais de Baixo Custo como Estratégia de Construção da Autonomia de Professores de Física: Uma experiência em Formação continuada. IX Encontro Nacional de Pesquisa em Ensino de Física. Anais...Jaboticatubas, MG: 2004

SANTOS, L. F.; PEREIRA, C. J. Composição de cores através da calibração radiométrica e fotométrica de LEDs: teoria e experimento. Revista Brasileira de Ensino de Física, v. 35, n. 2, p. 1-8, 2013.

SASAKI, D. G. G.; JESUS, V. L. B. DE. Avaliação de uma metodologia de aprendizagem ativa em óptica geométrica através da investigação das reações dos alunos. Revista

Brasileira de Ensino de Física, v. 39, nºㄹ, 2017.

SHULMAN, L. D.; TAMIR, P. Research on Teaching in the natural science. In: Second handbook of research on teching. Chicago: Rand MacNally, 1964. p. 1098-1148. SILVA, E. R. DA; MURAMATSU, M. O fenômeno do speckle como introdução à metrologia óptica no laboratório didático. Revista Brasileira de Ensino de Física, v. 29, n. 2, p. 283-286, 2007.

SILVA, J. C. X.; LEAL, C. E. S. Proposta de Laboratório de Física de baixo custo para Escolas da rede Pública de Ensino Médio. Revista Brasileira de Ensino de Física, v. 37, n. 2, v. 39, $\mathrm{n}^{\mathrm{o}} 1$, p. 1-5, 2017.

SILVEIRA, S.; GIRARDI, M. Desenvolvimento de um kit experimental com Arduino para o ensino de Física Moderna no Ensino Médio. Revista Brasileira de Ensino de Física, v. 
39, $\mathrm{n}^{\circ} 4,2017$.

SILVEIRA, M. V; BARTHEM, R. B. Ensino da visão cromática através de aparato com LED's coloridos. Revista Brasileira de Ensino de Fisica, v. 38, nº 3, $2016 \mathrm{a}$.

SILVEIRA, M. V; BARTHEM, R. B. Disco de Newton com LEDs. Revista Brasileira de Ensino de Física, v. 38, $n^{\circ}$ 4, $2016 b$.

SISMANOGLU, B. N. et al. A utilização da filmadora digital para o estudo do movimento dos corpos. Revista Brasileira de Ensino de Física, v. 31, n. n. 1, p. 1501, 2009.

SOARES, R. R.; BORGES, P. D. F. O plano inclinado de Galileu: uma medida manual e uma medida com aquisição automática de dados. Revista Brasileira de Ensino de Física, v. 32, n. 2, p. 1-11, 2010.

SOGA, D.; PAIVA JR., R. D.; MURAMATSU, M. Comprimento focal de lentes esféricas. Revista Brasileira de Ensino de Física, v. 39, nº3, p. e3506, 2017.

SOUZA, A. R. DE et al. A placa Arduino: uma opção de baixo custo para experiências de física assistidas pelo PC. Revista Brasileira de Ensino de Física, v. 33, n. 1, p. 01-05, 2011.

SOUZA, L. A. et al. Discutindo a natureza ondulatória da luz e o modelo da óptica geométrica através de uma atividade experimental de baixo custo. Revista Brasileira de Ensino de Física, v. 37, n. 4, p. 4311-1-4311-6, 2015.

STEWART, S. M. Some simple demonstration experiments involving homopolar motors.

Revista Brasileira de Ensino de Física, v. 29, n. 2, p. 275-281, 2007.

TOLEDO, R. S. et al. Haciendo hologramas en la escuela y en la casa. Revista brasileira de ensino ..., v. 32, n ${ }^{0} 3$, p. 1-7, 2010.

TRIANA, C. A.; FAJARDO, F. Experimental study of simple harmonic motion of a spring-mass system as a function of spring diameter. Revista Brasileira de Ensino de Física, v. 35, 4, p. 4305, 2013.

TRUMPER, R. The physics laboratory - a historical overview and future perspectives. Ciência \& Educação, v. 12, p. 645-670, 2003.

TURCHIELLO, R. DE F. et al. Efeito de Lente Térmica: uma demonstração de baixo custo para laboratórios de ensino sobre a capacidade da luz em modificar o índice de refração de um meio. Revista Brasileira de Ensino de Física, v. 38, n. 3, p. e3501-1-e3501-6, 2016. VERTCHENKO, L.; DICKMAN, A. G. Verificando a lei de Boyle em um laboratório didático usando grandezas estritamente mensuráveis. Revista Brasileira de Ensino de Física, v. 34, n ${ }^{\circ}$ 4, p. 4312, 2012.

VERTCHENKO, L.; VERTCHENKO, L. Verification of Malus's Law using a LCD monitor and Digital Photography. Revista Brasileira de Ensino de Física, v. 38, n. 3, 2016.

VIANA, J. C.; ARNOLD, F. Desenvolvimento de um sistema automatizado para medição de impedância elétrica. Revista Brasileira de Ensino de Física, v. 39, nº 2, e, 2017.

VILLALBA, J. M. et al. Estudio experimental de la inducción electromagnética entre dos bobinas: Dependencia con la corriente eléctrica. Revista Brasileira de Ensino de Física, v. 37, $\mathrm{n}^{\circ} 1$, p. 1-7, 2015.

VOSEGERAU, D. S. R.; ROMANOWSKI, J. P. Estudos de revisão : implicações conceituais e metodológicas. Revista Diálogo Educacional, v. 14, n. 41, p. 165-189, 2014.

VYGOTSKY, L. S. A construção do pensamento e da linguagem. São Paulo: Editora Martins Fontes, 2001.

ZABALA, A. A prática Educativa Como ensinar. $1^{\text {a }}$ ed. Porto Alegre: Artimed, 1998. 
Ensino \& Pesquisa, União da Vitória, v. 18, nº 1, p. 136-166, jan./abr., 2020. 166 